\title{
Gestão local e seu impacto no desempenho fiscal: análise dos municípios mineiros
}

\section{Ana Paula Karruz}

Universidade Federal de Minas Gerais (UFMG), Belo Horizonte, MG, Brasil

\section{André Machado Moraes}

Banco de Desenvolvimento de Minas Gerais (BDMG), Belo Horizonte, MG, Brasil

\section{Resumo}

O estudo busca elucidar e articular a gama de condicionantes do desempenho fiscal local, dimensionar a influência da gestão fiscal municipal nesse desempenho, e descrever como a qualidade da gestão fiscal se distribui entre municípios com diferentes características. Propõe um modelo conceitual e de regressão para o desempenho fiscal, tendo o Índice Firjan de Gestão Fiscal (IFGF) dos municípios de Minas Gerais como variável dependente. A identificação de efeitos apoia-se na natureza longitudinal dos dados (2007-2016) e na modelagem em painel. Transferências voluntárias da União e do governo estadual parecem favorecer o desempenho fiscal local, especialmente via investimentos. Um terço da variação do IFGF não pode ser atribuída às covariáveis e é tomada, por eliminação, como proxy para a qualidade da gestão fiscal. Esta apresenta moderada correlação com a população e mostra sinais de dependência espacial, com concentração de valores altos na região da capital.

Palavras-chave: gestão fiscal, municípios, Índice Firjan de Desempenho Fiscal (IFGF) 


\section{El impacto de la gestión local en el desempeño fiscal municipal: análisis de los municipios de Minas Gerais}

El estudio busca enumerar y articular la gama de condicionantes del desempeño fiscal local, dimensionar la influencia de la gestión fiscal municipal en ese desempeño, y describir cómo la calidad de la gestión fiscal se distribuye entre municipios con diferentes características. Propone un modelo conceptual y de regresión, teniendo el Índice Firjan de Gestión Fiscal (IFGF) como variable dependiente. La estrategia de identificación reside en el modelo de datos del panel, cubriendo el estado brasileño de Minas Gerais entre 2007 y 2016. Transferencias discrecionales de los gobiernos central e estadual parecen favorecer el rendimiento fiscal local, especialmente financiando inversiones. Un tercio de la variación del IFGF no puede ser atribuida a las covariables y es tomada, por eliminación, como proxy para calidad de la gestión fiscal. Esta presenta correlación moderada con la población y signos de dependencia espacial, con reaparición de valores más altos en la región de la capital del estado.

Palabras clave: gestión fiscal, municipios, Índice Firjan de Gestión Fiscal (IFGF)

\section{Local management's impact on fiscal performance: analysis of Minas Gerais municipalities}

The study aims at pinpointing and articulating the range of factors affecting local fiscal performance; assessing the influence of municipal fiscal management on such performance; and describing how the quality of fiscal management is distributed across municipalities with different characteristics. A conceptual and a regression model are proposed, taking the Firjan Fiscal Management Index (IFGF) as the dependent variable. The identification strategy relies on panel data modeling, covering Brazil's Minas Gerais state between 2007 and 2016. Discretionary transfers from central and state governments seem to favor local fiscal performance, mainly via funding of investments. About one third of IFGF's variation is not explained by the model; by elimination, residuals are interpreted as proxy for quality of local fiscal management. This measure shows a moderate correlation with population size and signs of spatial autocorrelation, with above-average values repeatedly detected near the state capital.

Keywords: fiscal management, municipalities, Firjan Fiscal Management Index (IFGF) 


\section{Introdução}

A centralidade do município na provisão de serviços públicos, combinada com uma variedade de parâmetros constitucionais e legais sobre arrecadação e despesas, além de flutuações conjunturais de natureza macroeconômica e política, exigem crescente capacidade de gestão fiscal local. Enquanto as capacidades estatais têm ganhado espaço na literatura sobre gestão e políticas públicas (e.g., CINGOLANI, 2013; CINGOLANI; THOMSSON; CRombrugghe, 2015; Gomide; BosCHI, 2016), o tema específico da capacidade de gestão fiscal permanece praticamente intocado.

Nesse quadro, o presente trabalho endereça as seguintes questões: i) Quais são e como se articulam os condicionantes do desempenho fiscal local? ii) Qual a magnitude da influência da gestão fiscal local nesse desempenho? iii) Como a qualidade da gestão fiscal se distribui entre municípios com diferentes características? Para tal, enfrenta o desafio teórico-conceitual de definição das noções de qualidade da gestão fiscal e de desempenho fiscal, bem como da formulação de um modelo que organize os elementos atuantes sobre o último. Diante da ainda dispersa literatura alusiva à pasta fiscal municipal - com importantes contribuições na Economia e na Ciência Política, porém carecendo de integração teórica - procede-se ao exercício de elencar os principais determinantes do desempenho fiscal, com base em bibliografia atinente a tópicos como gestão financeira em nível subnacional, federalismo fiscal e (des)centralização, distributive politics e ciclos políticos.

No ensaio empírico, para endereçar o desafio analítico de se isolar um fator específico - qualidade da gestão fiscal - num contexto de multicausalidade, a abordagem empregada consiste em demarcar a parcela de variação do desempenho fiscal que não pode ser atribuída a outros de seus condicionantes. Essa opção se justifica pela difícil apreensão da relação entre qualidade da gestão fiscal e desempenho fiscal, dada a indisponibilidade de instrumentos válidos para captar a primeira, e o potencial efeito heterogêneo desta em municípios de diferentes condições orçamentárias, socioeconômicas e políticas.

Assim, neste trabalho aplica-se uma estratégia de identificação por eliminação, amparada em dados de painel sobre desempenho fiscal, analisados via modelo de 
regressão, com efeitos fixos de município e de ano. Os resíduos da regressão-i.e., a variação do desempenho fiscal que não pode ser prevista pelo modelo - são compreendidos como expressão da qualidade da gestão fiscal.

Esta pesquisa visa adensar o debate acerca das finanças municipais, a partir da análise dos municípios mineiros no período 2006-2017. Minas Gerais é o estado com maior número de municípios (853) e se caracteriza por grande diversidade socioeconômica. O intervalo temporal considerado aproveita ao máximo a dimensão longitudinal das informações disponíveis. O modelo de regressão estimado possibilita controlar por fatores estruturais e conjunturais que influenciam o desempenho fiscal municipal, e é viabilizado por um esforço considerável de reunião de bases de dados. A concepção do referido modelo alicerça-se em levantamento bibliográfico abrangente, a partir do qual buscou-se integrar diferentes vertentes teóricas e condicionantes do desempenho fiscal. Essa articulação conceitual, acredita-se, também se configura como uma contribuição do estudo.

O trabalho está dividido em quatro seções, além desta introdução. Começando pelo desafio teórico-conceitual, a próxima seção ocupa-se de propor uma definição para gestão fiscal e outra para desempenho fiscal, e lista fontes de variação do desempenho no contexto dos municípios brasileiros, do ponto de vista temporal e espacial. Na seção 3, detalham-se dados e métodos empregados; na seção 4, apresentam-se os resultados das regressões e examinam-se os resíduos. Na seção 5, recapitulam-se os achados e tecem-se as considerações finais.

\section{Gestão e desempenho fiscal}

\subsection{Conceitos e mensuração}

A capacidade de agentes do Estado implantarem decisões e alcançarem os objetivos traçados pelo governo, exercendo um papel promotor do desenvolvimento, vem recebendo interesse crescente na literatura sobre gestão e políticas públicas. Uma multiplicidade de capacidades tem sido identificada, em dimensões tais como capacidade burocrática ou administrativa, coercitiva (capacidade de garantir a ordem e prevenir conflitos), e capacidade 
fiscal - ou de "extração" - para financiar a provisão de serviços (CINGOLANI, 2013; CINGOLANI; Thomsson; Crombrugghe, 2015). No tocante à última, nota-se um foco no esforço arrecadatório, com ênfase na função tributária; por exemplo, em Cingolani, Thomsson e Crombrugghe (2015), oito dos nove indicadores de capacidade fiscal tratam de taxação, enquanto o nono reporta a exportação de commodities. Dessa forma, limita-se o processo de gestão fiscal a apenas um de seus componentes, ignorando-se escolhas sobre gastos e resultados orçamentários.

Importante referência no campo das capacidades e do desempenho governamental, o Government Performance Project (GPP) conceituou e mensurou capacidades de gestão financeira governamental. Nascido na Maxwell School of Citizenship and Public Affairs, da Syracuse University, e depois conduzido pelo Pew Research Center, o GPP analisou, por mais de uma década (1996-2010), cinco subsistemas de capacidades de gestão de agências federais, estados, condados e grandes cidades dos Estados Unidos, sendo eles: gestão financeira, de capital, de pessoas, de tecnologia da informação e de resultados (INGRAHAM; JOYCE; DONAHUE, 2003; INGRAHAM, 2007).

Embora reconheça que a tradução de capacidades de gestão em bom desempenho não seja direta nem imediata, o GPP priorizou o estudo dessas capacidades, em vez de resultados fiscais, justamente devido à gama diversificada de influências sobre estes, muitas das quais posicionadas completamente fora do alcance de gestores locais, como explica Hou (2007). O autor sintetiza os achados do GPP quanto à capacidade de gestão financeira de mais de 120 entes subnacionais americanos ${ }^{1}$, a partir de três domínios: perspectiva orçamentária plurianual; mecanismos de preservação da estabilidade e saúde fiscal; disponibilidade de informações e controle sobre operações financeiras. O Quadro 1 reproduz os domínios e critérios que os operacionalizam, com o propósito de substanciar a detalhada e compreensiva visão de capacidades adotada pelo GPP. 
Quadro 01 | Domínios e critérios para avaliação da capacidade de gestão financeira utilizados pelo GPP

\begin{tabular}{|l|l|}
\hline Domínio & Critérios de avaliação \\
\hline $\begin{array}{l}\text { Tempestividade da adoção do orçamento (dado o caráter } \\
\text { intensamente político das deliberações envolvendo a peça } \\
\text { orçamentária, a habilidade de aprová-la em tempo para um novo } \\
\text { ano fiscal seria um indicador positivo do ambiente político da } \\
\text { gestão fiscal) }\end{array}$ \\
\hline Elurianualidade & $\begin{array}{l}\text { Equilíbrio estrutural entre receitas correntes e despesas correntes } \\
\text { os subsequentes }\end{array}$ \\
\hline $\begin{array}{l}\text { Avaliação do impacto fiscal futuro das principais decisões de } \\
\text { políticas públicas }\end{array}$ \\
\hline $\begin{array}{l}\text { Existência de dispositivos fiscais anticíclicos (e.g., fundos de } \\
\text { estabilização orçamentária - rainy-day funds) }\end{array}$ \\
\hline $\begin{array}{l}\text { Atributos da política de gestão de dívidas (e.g., composição } \\
\text { de organismos de controle constituídos para aconselhar, }\end{array}$ \\
\hline supervisionar e rever operações de contratação de crédito) \\
\hline $\begin{array}{l}\text { Atributos da gestão de investimentos (e.g., metodologia para } \\
\text { valoração de portfólio e existência de cronograma de revisão } \\
\text { dessa valoração) }\end{array}$ \\
\hline $\begin{array}{l}\text { Tempestividade e confiabilidade do reporte financeiro ao público } \\
\text { em geral }\end{array}$ \\
\hline informações e controle \\
sobre operações financeiras
\end{tabular}

Fonte: elaboração própria, com base em Hou (2007).

Levantamentos do tipo realizado pelo GPP são complexos e custosos, envolvendo a elaboração de instrumentos de coleta para diferentes níveis de governo. No Brasil, uma iniciativa do Instituto de Pesquisa Econômica Aplicada (Ipea), em parceria com instituições de planejamento, pesquisa e estatística de sete estados, inspirou-se no questionário do GPP e o adaptou à realidade brasileira, produzindo a publicação Gestão municipal no Brasil: um retrato das prefeituras (VELoso et al., 2011). O estudo, com dados de 2010, baseou-se nas respostas de gestores públicos de uma amostra de 194 municípios, distribuídos pelos estados de Alagoas, Espírito Santo, Pará, Paraíba, Paraná, Rio de Janeiro e São Paulo. 
Da mesma forma como fizeram Veloso et al. (2011, p. 19), para os fins deste trabalho, gestão financeira² será entendida como o conjunto de ações incidentes "sobre alocação do orçamento, previsão, execução orçamentária, contabilidade, relatórios financeiros e gestão da dívida e do investimento". No tocante à dimensão fiscal das capacidades estatais, o questionário de Veloso et al. (2011) explora os tópicos listados no Quadro 2, o qual apresenta também os principais achados desses autores nesse subsistema.

Quadro 02 | Critérios para avaliação da capacidade de gestão financeira utilizados por Veloso et al. (2011) e respectivos achados

\section{Critério}

Existência de estrutura organizacional dedicada e seu posicionamento hierárquico no organograma do governo municipal

Prática de terceirização de serviços de contabilidade

Informatização de processos:

arrecadação de tributos, contabilidade, controle da execução do plano plurianual (PPA), da lei orçamentária anual (LOA) e da dívida ativa

Escolaridade dos funcionários e ações para sua qualificação

Elaboração de estudos socioeconômicos para orientar o planejamento financeiro

Disponibilização de informações atualizadas das dotações orçamentárias para secretários e diretores

\section{Achados}

Mais da metade das prefeituras analisadas possui secretaria de finanças; municípios com menos de 20 mil habitantes são menos prováveis de apresentar essa estrutura.

Pequenos municípios são os que mais recorrem a serviços externos de contabilidade. Terceirização é mais frequente em municípios que têm secretaria exclusiva.

Imensa maioria dos processos são informatizados; no Pará, estado com menor média de informatização de processos de gestão financeira, $80 \%$ deles encontram-se informatizados.

Há ampla discrepância regional na escolaridade formal dos funcionários envolvidos com a gestão financeira. Com exceção de municípios do Paraná e de São Paulo, na maioria das prefeituras não existem ações de qualificação.

Metade dos municípios pesquisados declara elaborar estudos socioeconômicos para apoiar o planejamento, porém não se sabe sobre a qualidade desses estudos.

Cerca de $90 \%$ dos municípios disponibilizam a secretários e diretores informações atualizadas sobre dotações orçamentárias; há pouca variação regional nesse quesito. 


\section{Critério}

Esforço tributário, medido pela noção oposta: defasagem da legislação da planta genérica de valores, do cadastro do imposto sobre propriedade (IPTU) e da legislação do imposto sobre serviços (ISS)

Estratégia de financiamento de déficit orçamentário (e.g., aumento da arrecadação, captação de transferências voluntárias)

Participação da sociedade civil na elaboração do PPA e da LOA

\section{Achados}

Defasagem média da planta genérica de valores é de 8 anos. Quanto ao cadastro do IPTU, a defasagem média é de 4,3 anos entre os municípios de grande porte, e de 6,6 entre os de médio porte. A maior defasagem na legislação do ISS é encontrada em municípios pequenos (5,3 anos).

Um terço dos municípios declara financiar dívidas via aumento da arrecadação, enquanto $40 \%$ afirma buscar transferências voluntárias para esse fim.

Mais de dois terços dos municípios informaram que a sociedade civil participa da elaboração do PPA e da LOA.

Fonte: elaboração própria, com base em Veloso et al. (2011).

O apontamento de Veloso et al. (2011) sobre as disparidades na escolaridade e qualificação da burocracia merece atenção, tendo em vista trabalhos que indicam haver impacto dessa profissionalização no desempenho fiscal. Batista (2015) encontrou uma associação negativa entre o quantitativo de funcionários e sua qualificação, de um lado, e os registros de erros durante a implementação de políticas públicas (e.g., a não comprovação dos valores transferidos a fornecedores), de outro. Inobstante, a hipótese de que uma burocracia estatutária, por ser menos influenciada pela esfera política, apresentaria melhores resultados na implementação das políticas não mostrou sustentação empírica em Batista (2015). A seu turno, Marenco, Strohschoen e Joner (2017) examinaram a hipótese de que a profissionalização da burocracia, conceito que combina expertise técnica com a autonomia e estabilidade de carreiras públicas, reduziria os custos de transação políticos da tributação imobiliária em pequenas localidades. Os autores observaram que a proporção de estatutários com formação superior entre servidores públicos nas administrações municipais brasileiras correlaciona-se positivamente com a arrecadação tributária municipal.

O conceito de desempenho fiscal é aqui entendido, de forma ampla, como os resultados fiscais alcançados pela administração pública. Para operacionalizá-lo, ao invés de dimensões ou indicadores parciais, opta-se pela formulação empregada no Índice Firjan de Gestão Fiscal (IFGF), que monitora resultados fiscais dos municípios a partir de 2006 (SISTEMA FIRJAN, 2017a). O momento de início da série é oportuno, uma vez que houve mudanças na forma da declaração à Secretaria do Tesouro Nacional (STN, fonte 
do IFGF) em 2002, requerendo que os municípios reorganizassem sua contabilidade para adesão ao novo plano de contas (GOBETTI; KLERING, 2007)³. O IFGF é composto por cinco indicadores, detalhados no Quadro 3. Tanto os indicadores quanto o próprio IFGF variam entre zero e um: quanto maior a pontuação, melhor a situação fiscal do município.

Quadro 03 | Composição do IFGF

\begin{tabular}{|c|c|c|c|}
\hline Dimensão & Foco & Indicador & Peso (\%) \\
\hline Receita própria & $\begin{array}{l}\text { Capacidade } \\
\text { arrecadação }\end{array} \quad$ de & $\begin{array}{l}\text { Receita própria / } \\
\text { Receita corrente líquida }\end{array}$ & 22,5 \\
\hline Rigidez orçamentária & Gastos com pessoal & $\begin{array}{l}\text { Gastos com pessoal / } \\
\text { Receita corrente líquida }\end{array}$ & 22,5 \\
\hline Liquidez & Suficiência de caixa & $\begin{array}{l}\text { (Caixa - Restos a pagar) / } \\
\text { Receita corrente líquida }\end{array}$ & 22,5 \\
\hline Investimentos & $\begin{array}{l}\text { Capacidade de fazer } \\
\text { investimentos }\end{array}$ & $\begin{array}{l}\text { Investimentos / } \\
\text { Receita corrente líquida }\end{array}$ & 22,5 \\
\hline Custo da dívida & Custo da dívida & $\begin{array}{l}\text { Juros e amortizações / } \\
\text { Receita líquida real }\end{array}$ & 10,0 \\
\hline
\end{tabular}

Notas: Receita corrente líquida = total das receitas - (contribuições dos servidores para custeio de seu sistema de previdência e assistência social, e receitas provenientes da compensação financeira dos diversos regimes de previdência social). Receita líquida real = total das receitas - (receitas provenientes de operações de crédito, de alienação de bens, de transferências voluntárias ou de doações recebidas com o fim específico de atender a despesas de capital).

Fonte: elaboração própria, com base em Sistema Firjan (2017a).

Conforme apurado pelo Sistema Firjan (2017a), os principais desafios fiscais dos municípios brasileiros são estruturais. O alto comprometimento dos orçamentos com a folha de pagamento (uma despesa obrigatória) e a dependência das transferências intergovernamentais expõem os municípios à vulnerabilidade em tempos de baixa econômica, com prejuízo dos esforços de investimento. O acesso restrito ao mercado de crédito redunda no uso recorrente dos restos a pagar como fonte de financiamento. Em Minas Gerais, o IFGF médio em 2016 (0,4642), último ano-base disponível à época de elaboração deste trabalho, ficou próximo à média nacional $(0,4655)$. Somente $3,1 \%$ dos municípios mineiros gastaram mais de $60 \%$ com pagamento do funcionalismo, em contraste com o percentual nacional de 12,7\% (SISTEMA FIRJAN, 2017b).

É possível que o IFGF apresente um viés positivo em municípios de maior porte; isso porque as dimensões receita própria e investimento tendem a se sobressair em orçamentos de localidades com expressiva escala populacional. Além disso, dado o 
caráter arbitrário dos pesos e intervalos de pontuação de cada indicador parcial, o índice se torna passível de críticas. Por exemplo, a municípios que gastam com pessoal $30 \%$ ou menos da sua receita corrente líquida $(R C L)$ é atribuída a nota máxima (SISTEMA FIRJAN, 2017c), limiar provavelmente baixo diante da centralidade desses entes na prestação de serviços públicos intensivos em trabalho. Outrossim, Gobetti e Klering (2007) defendem que o bom desempenho em índices fiscais não pode ser tomado como sinônimo de gestão exitosa - existindo justamente um trade-off no qual municípios com boa performance nesses índices tendem a apresentar níveis mais baixos de investimento em infraestrutura e na área social, exigindo uma reflexão sobre a qualidade do ajuste fiscal. Mesmo com limitações, o IFGF continua sendo uma medida útil para o desempenho fiscal, por apresentar dados padronizados sob uma mesma metodologia para um recorte temporal consideravelmente largo, além de abarcar diferentes aspectos do desempenho fiscal.

\subsection{Múltiplas influências sobre o desempenho fiscal}

Decisões que importam para o desempenho fiscal do município originam-se em deliberações de legisladores e outros agentes políticos, beneficiando-se da capacidade técnica da burocracia estatal e demais capacidades de gestão, como elencadas no âmbito do GPP e levantadas por Veloso et al. (2011). Ademais, há questões de caráter estrutural, a exemplo daquelas atinentes à distribuição de poder arrecadatório entre entes (e suas respectivas obrigações na prestação de serviços públicos), bem como o ano de criação: municípios mineiros mais recentemente emancipados são os mais dependentes das transferências da União (ARAÚJO JÚNIOR, 2016). Não menos importantes, figuram também aspectos contextuais, muitos dos quais posicionados fora do alcance de atuação de gestores locais.

Propõe-se aqui uma forma de descrição dessa multiplicidade de influências, tratando-se de um esforço de organização teórica que empresta conceitos e hipóteses de diferentes linhas temáticas, como as do federalismo fiscal e dos ciclos políticos. A enumeração de fatores apoiou-se em considerações sobre a natureza de sua variação, no tempo e no espaço (Quadro 4). Assim, entendem-se como estruturais fatores que permanecem constantes durante longos intervalos temporais, e que podem ou não variar entre localidades. Quando não diferem entre os municípios, são aqui referidos como institucionais. Fatores conjunturais alteram-se em maior frequência, podendo 
ser específicos de uma localidade ou atingir todas.

\section{Quadro 04 | Principais influências sobre o desempenho fiscal municipal, por natureza de variação}

\begin{tabular}{|c|c|c|c|c|}
\hline \multirow{3}{*}{$\begin{array}{l}\text { Varia en- } \\
\text { tre muni- } \\
\text { cípios? } \\
\text { Não }\end{array}$} & \multicolumn{4}{|c|}{ Varia frequentemente? } \\
\hline & \multicolumn{2}{|c|}{ Não (fatores estruturais) } & \multicolumn{2}{|c|}{ Sim (fatores conjunturais) } \\
\hline & $\begin{array}{l}\text { Fatores (institucionais): } \\
\text { - Limites constitucionais da } \\
\text { tributação municipal } \\
\text { - Regras para } \\
\text { transferências não } \\
\text { discricionárias } \\
\text { - Centralização do policy } \\
\text { decision-making (e.g., } \\
\text { percentuais mínimos } \\
\text { de gastos em saúde e } \\
\text { educação) } \\
\text { - Determinações da Lei de } \\
\text { Responsabilidade Fiscal } \\
\text { (LRF) }\end{array}$ & $\begin{array}{l}\text { Referências: } \\
\text { - Arretche (2004); } \\
\text { - Baião, Cunha e } \\
\text { Souza (2017); Veloso } \\
\text { et al. (2011); } \\
\text { - Arretche (2012); } \\
\text { - Sistema Firjan } \\
\text { (2017a). }\end{array}$ & $\begin{array}{l}\text { Fatores: } \\
\text { - Contexto fiscal (federal, } \\
\text { estadual) } \\
\text { - Contexto econômico } \\
\text { (nacional, estadual) }\end{array}$ & $\begin{array}{l}\text { Referências: } \\
\text { - Sistema Firjan (2017a); } \\
\text { - Sistema Firjan (2017a). }\end{array}$ \\
\hline Sim & $\begin{array}{l}\text { Fatores (estruturais } \\
\text { locais): } \\
\text { - Ano de criação } \\
\text { - Outros fatores estruturais } \\
\text { locais, tais como: } \\
{ }^{\circ} \text { Recursos naturais } \\
{ }^{\circ} \text { Principais atividades } \\
\text { econômicas estabelecidas } \\
{ }^{\circ} \text { Infraestrutura instalada } \\
{ }^{\circ} \text { Extensão territorial } \\
\text { o Status de capital } \\
{ }^{\circ} \text { Proximidade com } \\
\text { cidades-polo }\end{array}$ & $\begin{array}{l}\text { Referências: } \\
\text { - Araújo Júnior (2016) } \\
\text { - (Autores do presente } \\
\text { trabalho reputam } \\
\text { estes fatores como } \\
\text { influentes sobre } \\
\text { a capacidade de } \\
\text { arrecadação própria } \\
\text { e a demanda por } \\
\text { serviços públicos) }\end{array}$ & $\begin{array}{l}\text { Fatores: } \\
\text { - Contexto fiscal } \\
\text { (municipal) } \\
\text { - Potencial de } \\
\text { arrecadação própria } \\
{ }^{\circ} \text { Contexto econômico } \\
\text { (municipal) } \\
\text { - Tamanho populacional } \\
\text { (base de arrecadação) } \\
\text { - Demanda por serviços } \\
\text { públicos (escala e } \\
\text { complexidade) } \\
\text { - Capacidade de atração } \\
\text { de recursos públicos* } \\
\text { (alinhamento partidário) } \\
\text { - Transferências } \\
\text { intergovernamentais } \\
\text { (realizadas) } \\
{ }^{\circ} \text { Compulsórias } \\
\text { redistributivas } \\
\text { (influxo de baixo custo) } \\
\text { •Voluntárias } \\
\text { - Ciclos políticos } \\
{ }^{\circ} \text { Alternância ideológica } \\
{ }^{\circ} \text { Ano eleitoral } \\
\text { }{ }^{\circ} \text { Probabilidade de } \\
\text { manutenção do } \\
\text { incumbente ou seu } \\
\text { grupo no poder } \\
\text { - Qualidade da gestão } \\
\text { fiscal }\end{array}$ & $\begin{array}{l}\text { Referências: } \\
\text { - Sistema Firjan (2017a); } \\
\text { - Soares e Melo (2016); } \\
\text { Veloso et al. (2011) } \\
\text { - Gobetti e Klering (2007); } \\
\text { - Bueno (2018); Puttomatti } \\
\text { (2013); Stokes et al. (2013) } \\
\text { - Baião, Cunha e Souza } \\
\text { (2017); Brollo e Nannicini } \\
\text { (2012); Bueno (2018); } \\
\text { Costa e Castelar (2015); } \\
\text { Mattos, Rocha e Arvate } \\
\text { (2011); Meireles (2019); } \\
\text { Nunes (2015); Prado } \\
\text { (2001); Puttomatti (2013); } \\
\text { Sakurai (2013); Soares e } \\
\text { Melo (2016); } \\
\text { - Alesina (1987); Hibbs Jr. } \\
\text { (1977); Nordhaus (1975); } \\
\text { Rogoff e Sibert (1988); } \\
\text { Sakurai (2009); Sakurai e } \\
\text { Gremaud (2007) } \\
\text { - Batista (2015); } \\
\text { Cingolani (2013); } \\
\text { Cingolani, Thomsson e } \\
\text { Crombrugghe (2015); } \\
\text { Hou (2007); Ingraham } \\
\text { (2007); Ingraham, Joyce e } \\
\text { Donahue (2003); Marenco, } \\
\text { Strohschoen e Joner } \\
\text { (2017); Veloso et al. (2011) }\end{array}$ \\
\hline
\end{tabular}

Nota: * Por exemplo, transferências voluntárias do estado ou da União para entidades privadas da assistência social e investimentos diretos dessas esferas em infraestrutura de transportes.

Fonte: elaboração própria. 
Os contextos econômico e fiscal das demais esferas de governo são fatores conjunturais, assim como as influências próprias às localidades e que se modificam no tempo, a exemplo do contexto econômico e fiscal local, do tamanho populacional (e consequente base arrecadatória), da escala e complexidade ${ }^{4}$ da demanda por serviços públicos, da capacidade de atração de recursos públicos (e.g., obras e equipamentos públicos destinados ao município em razão de alinhamento partidário com outros níveis de governo), das transferências intergovernamentais, das prioridades de governo dado o ciclo político, e da qualidade da gestão fiscal. Assumindo-se que esta seja sensível a mudanças na burocracia (como ingresso ou saída de técnicos), às preferências dos representantes e à acomodação de interesses ou ao aprendizado durante o mandato, admite-se que a qualidade da gestão fiscal varie com certa frequência. Alguns desses fatores são discutidos a seguir, com ênfase nos institucionais, transferências e ciclos políticos.

Na elaboração da Constituição Federal de 1988 (CF88), a busca por direitos individuais e coletivos entrelaçou-se com demandas referentes à descentralização. Em função disso, a CF88 aprofundou a descentralização política (municípios passaram a eleger seus representantes legais sem o crivo das instâncias estadual e federal), administrativa (receberam responsabilidades adicionais na execução de uma série de políticas, sobretudo sociais) e fiscal (com transferências intergovernamentais incrementadas e maior autonomia para legislar sobre tributos próprios), ensina Arretche (2004).

Ao se descentralizar a gestão pública, tomou-se o que se julgou ser o "caminho mais adequado para aumentar a eficiência no uso dos recursos, a eficácia das políticas públicas, a transparência das decisões e a geração de condições propícias à responsabilização dos governantes perante seus cidadãos" (VELoso et al., 2011, p. 13). A reboque, com atribuições crescentes na oferta de serviços públicos, revelou-se a necessidade de profissionalização da gestão fiscal local, visto que boa parte dos municípios não dispunha de capacidade técnica e administrativa para prover serviços públicos, fator acentuado pelo desequilíbrio inter e intra-regional, anteciparam Rezende e Afonso (1987).

A expansão das receitas se deu, via de regra, a partir do aumento das transferências constitucionais, através de mecanismos como o Fundo de Participação dos Municípios (FPM). Previamente à CF88, o fundo era composto por $17 \%$ dos valores arrecadados sobre

\footnotetext{
${ }^{4}$ Complexidade é aqui entendida como grau de deficiência no desenvolvimento social e econômico, relativamente a outros municípios. Não se trata, portanto, do nível de sofisticação dos serviços necessários para sanar essa deficiência.
} 
o Imposto sobre Produtos Industrializados (IPI) e o Imposto de Renda (IR); a CF88 elevou a participação do FPM gradativamente para $22,5 \%$, percentual depois aumentado para 23,5\% (Emenda Constitucional no 55/2007), chegando a 24,5\% em 2016, pela Emenda Constitucional no 84/2014 (STN, 2018).

Municípios de pequeno porte são beneficiados pelas regras de redistribuição dos recursos tributários, e comumente dependem do FPM. Sobre isso, Baião, Cunha e Souza (2017, p. 603) ponderam: “o FPM parte do pressuposto de que municípios menores serão também os que mais necessitam de recursos, mas estes não têm necessariamente uma elevada proporção da população em situação de extrema pobreza, e não apresentam PIB 'per capita' sempre pequeno". Esses autores apuram que transferências sociais, como as do Fundeb ${ }^{5}$ e do SUS $^{6}$, contribuem mais para a equalização fiscal ${ }^{7}$ que o próprio FPM, a despeito da vocação redistributiva deste.

Os grandes municípios, apesar de serem financiadores líquidos dos demais e de enfrentarem demandas sociais mais variadas, desfrutam de uma maior arrecadação própria, além de receberem um percentual mais elevado do Imposto sobre Circulação de Mercadorias e Prestação de Serviços (ICMS). Comparativamente, municípios de médio porte acabam em situação fiscal desvantajosa, dada sua limitada arrecadação própria e por não serem particularmente favorecidos na repartição dos recursos (VEloso et al., 2011).

Se, de um lado, repasses do FPM aliviam a pressão orçamentária local, nesse sentido facilitando a gestão fiscal, de outro podem associar-se a ineficiências. O aumento do volume de repasse do FPM incentivou o surgimento de municípios em grande monta até 1996, quando as regras foram alteradas (VELoso et al., 2011; ARAúJO JúNIOR, 2016). Ainda, a noção do flypaper effect, segundo a qual transferências intergovernamentais estimulam mais as despesas locais do que variações na renda, postula que as administrações tenderão a gastar menos eficientemente as transferências não condicionadas (como o FPM), porque essas gestões não arcam com o custo político e administrativo de levantar tais valores junto à população. Mattos, Rocha e Arvate (2011) encontraram uma associação positiva entre contratação de pessoal e aumento

\footnotetext{
${ }^{5}$ Fundo de Manutenção e Desenvolvimento da Educação Básica e de Valorização dos Profissionais da Educação.

${ }^{6}$ Sistema Único de Saúde.

${ }^{7}$ Baião, Cunha e Souza (2017) definem equalização fiscal como redução do gap entre as necessidades fiscais para provisão de serviços públicos e a capacidade arrecadatória de um ente.
} 
de transferências, e um esforço de eficiência arrecadatória relacionado à elevação da renda, portanto sugerindo uma menor eficiência relativa dos repasses públicos. Sakurai (2013) também reportou maior sensibilidade dos gastos públicos municipais diante de transferências governamentais em comparação com incrementos da renda local. Já Costa e Castelar (2015) não identificaram a presença de flypaper effect, mesmo após analisarem municípios em diferentes quantis de despesas municipais.

Enquanto as regras para repasses não discricionários são definições institucionais, valores efetivamente recebidos pelos municípios variam no tempo e entre municípios. No caso do FPM, o montante repassado a cada decêndio (intervalo de 10 dias) é proporcional à arrecadação de IPI e IR no decêndio anterior - portanto, flutuante e sensível ao contexto macroeconômico (STN, 2018). Também, as estimativas anuais da população municipal e da renda per capita de cada estado formam a base para o cálculo dos percentuais individuais de participação dos municípios no FPM (STN, 2018), configurando outra fonte de variação desse influxo.

O fortalecimento local, com incremento das receitas, foi seguido de uma tentativa de avigoramento da capacidade financeira da União. Na década de 1990, a União iniciou um movimento de reestruturação de sua arrecadação, baseando-se principalmente nas contribuições sociais (SOARES; MELO, 2016). Com o enfoque da União nos encargos sociais, houve uma diminuição nos valores arrecadados através dos impostos mais tradicionais, como IR e IPI, o que impactou negativamente o montante repassado ao FPM (OLIVEIRA, 2007).

Ademais, a regulação central da operação dos entes subnacionais reteve na União poder de decisão (policy decision-making) sobre as políticas públicas locais (ARRETCHE, 2012). Exemplo disso são os gastos mínimos constitucionais do município com saúde e educação, respectivamente $15 \%$ e $25 \%$ das receitas oriundas de impostos, incluídas as transferências constitucionais. Outro exemplo é a Lei Complementar no 101/2000 (Lei de Responsabilidade Fiscal - LRF), que impõe aos municípios obrigações (e.g., declaração de contas para a STN, art. 48 e 51; encerramento do mandato com recursos em caixa suficientes para honrar restos a pagar, art. 42) e limites (e.g., 60\% da RCL para gastos com pessoal, art. 19 e 20); os indicadores do IFGF foram concebidos de forma a atribuir valor mais baixo a municípios que não estejam em conformidade com a LRF (SISTEMA FIRJAN, 2017a). 
No modelo proposto para desempenho fiscal (Quadro 4), fatores como as prerrogativas e os limites da arrecadação municipal, as regras de distribuição do FPM, a centralização do policy decision-making e os dispositivos da LRF são considerados estáticos no curto prazo e incidentes sobre todos os municípios, indistintamente. Por outro lado, influências como o fluxo de transferências governamentais e as implicações dos ciclos políticos (exceto ano eleitoral) são tomadas como dinâmicas e variáveis entre localidades.

O impacto de decisões de política pública na economia, mais especificamente no desempenho fiscal, é analisado na literatura com base na ideia dos ciclos políticos, desenhados a partir da "possibilidade de fatores políticos afetarem o comportamento das variáveis econômicas" (SAKURAI, 2009, p. 40). Na bibliografia sobre ciclos políticos, é possível identificar duas correntes: a dos ciclos partidários e a dos ciclos eleitorais.

Os ciclos partidários ocorreriam em função da ideologia do partido no poder, influenciando a condução da política econômica (HIBBS JR., 1977; ALESINA, 1987; SAKURAI; GREMAUD, 2007). Esses ciclos seriam acentuados em caso de alternância no poder entre partidos com visões substantivamente diferentes.

A seu turno, a vertente dos ciclos eleitorais defende que policymakers, independentemente da ideologia, têm como objetivo primário a sua manutenção no poder. Dessa maneira, o gestor poderia promover alterações, possivelmente irresponsáveis, na política fiscal, em áreas mais sensíveis ao eleitorado, visando aumentar as chances de reeleição ou buscando assegurar a vaga para algum aliado (NoRDHAUS, 1975; Rogoff; SiBERT, 1988). Estratégias dessa espécie podem, ainda, emergir em um cenário de baixa probabilidade de manutenção do incumbente (ou de seu grupo) no poder, prejudicando o legado a ser entregue ao próximo policymaker.

Também contingente a fatores políticos, transferências voluntárias, oriundas da União ou dos estados, afrouxam restrições orçamentárias, favorecendo o desempenho fiscal do município. Esses repasses representam importante fonte de financiamento de políticas públicas, especialmente na viabilização de investimentos (SOARES; MELO, 2016).

Os condicionantes dos repasses discricionários têm sido classificados como redistributivos, político-partidários e técnicos (SOARES; MELO, 2016). O condicionante redistributivo é entendido como um aporte aos municípios que enfrentam dificuldades 
orçamentárias, visando garantir a continuidade da prestação de serviços municipais (PRADO, 2001). Contudo, Nunes (2015) e Baião, Cunha e Souza (2017) não encontraram evidências que apontassem para uma natureza redistributiva das transferências voluntárias da União (TVU) ${ }^{8}$.

Ao refutarem a motivação redistributiva, Baião, Cunha e Souza (2017) asseveram que as transferências voluntárias seguem estratégias político-partidárias. Esse argumento ampara-se na literatura de distributive politics, campo voltado ao estudo de como partidos políticos alocam bens e serviços públicos (STOKES et al., 2013; NUNES, 2015; BUENO, 2018). A noção central é que incumbentes tenderiam a repassar maiores montantes aos estados ou municípios liderados por aliados políticos, visando à fidelização do eleitorado. Brollo e Nannicini (2012) observam que em municípios onde prefeitos da oposição elegeramse por uma estreita margem, o montante das TVU tende a ser mais baixo, dificultando assim que esses adversários políticos vençam as eleições seguintes. A partir de um estudo comparativo de quatro países (Argentina e Venezuela, centralizados; Brasil e México, descentralizados), Nunes (2015) conclui que em países descentralizados, presidentes tendem a distribuir TVU de modo a favorecer prefeitos do seu partido, mesmo que tais localidades tenham expressiva massa de eleitores de oposição. Essa tática evita que o crédito político decorrente da despesa federal venha a ser capturado por políticos locais de oposição. Do lado da demanda, prefeitos da coalizão que ocupa a presidência tendem a apresentar maior número de propostas de convênio (o instrumento típico de contratação de transferência voluntária) e com valores mais vultosos, ao passo que prefeitos opositores, não vislumbrando a mesma chance de receber recursos, poupariam esforços, enviando menos propostas (MEIRELES, 2019).

Entretanto, pode ser estratégico repassar recursos para municípios cujos incumbentes são de partidos opositores. Essa lógica é arrazoada do ponto de vista de que o cidadão atribui seu bem-estar não apenas ao prefeito, próximo de si, mas a todas as esferas de governo. Assim, o cálculo político do volume de transferências que será repassado a cada localidade opositora, e a qual recipiente (prefeitura ou organização não estatal provedora de serviços

\footnotetext{
${ }^{8}$ Bertholini, Pereira e Rennó (2018) detectam efeitos positivos das TVU originadas por emendas parlamentares sobre indicadores de saúde, educação, emprego e renda. Todavia, tal impacto parece seguir um padrão de retornos decrescentes, dissipando-se após anos de recebimento continuado. Salienta-se que Bertholini e colegas (2018) analisam os efeitos das TVU, e não a distribuição dessas transferências.
} 
públicos) deve levar em conta o risco de credit hijacking ${ }^{9}$ e a probabilidade de conquistar novos votos, especialmente daqueles eleitores que não possuem forte laço ideológico com algum partido, os swing voters (PUTTOMATTI, 2013; BUENO, 2018).

Finalmente, a literatura aponta para o papel do perfil técnico das burocracias dos estados e municípios na angariação de transferências voluntárias. Soares e Melo (2016) encontram evidência de que, contrariando o condicionante redistributivo, entes mais ricos e desenvolvidos obtiveram parcelas maiores das transferências. Os autores explicam esse achado pela capacidade técnica das burocracias desses lugares, a qual apresentaria maior expertise na formulação de convênios, além de a aglomeração urbana demandar pesados investimentos em obras públicas.

Ainda, cabe considerar as influências de repasses intergovernamentais sobre o desempenho fiscal mensurado pelo IFGF. Cotas do FPM e transferências voluntárias ampliam a $\mathrm{RCL}$, deprimindo o indicador de receita própria, tudo o mais constante. As transferências voluntárias, de natureza extraordinária, muitas vezes são empregadas na realização de investimentos, nesse sentido favorecendo potencialmente o indicador respectivo; diferem, assim, do FPM, que é regular e tende a ser aplicado em custeio. Quanto ao custo da dívida, uma elevação (ou redução) das transferências voluntárias não afeta a receita líquida real (RLR) e não deve influir no indicador, ceteris paribus; já a cota do FPM, que compõe a RLR, tende a torná-lo mais positivo. Paira ainda a suspeita de flypaper effect, segundo a qual a aplicação de transferências - especialmente as do FPM, por representarem influxo de baixo custo político e administrativo - seria menos eficiente que a da arrecadação própria, complicando a formação de expectativas quanto ao sinal da relação entre esses repasses e o IFGF, em particular no que se refere aos indicadores de gastos com pessoal e suficiência de caixa. 


\section{Modelagem empírica e hipóteses}

O modelo empírico (Equação I) ${ }^{10}$ estrutura-se em torno de variações espaciais e temporais, podendo ser representado pelos mesmos quadrantes do Quadro 4. Tem o IFGF como variável dependente, e combinações município-ano (i-t) como unidade de análise.

$\mathbf{y}_{\mathrm{it}}=\alpha+\boldsymbol{\beta} \mathbf{C}_{\mathrm{it} ;(\mathrm{t}-1)}+\mathbf{a}_{\mathrm{i}}+\mathbf{b}_{\mathrm{t}}+\boldsymbol{\varepsilon}_{\mathrm{it}}$

Fatores institucionais, incidentes sobre todos os municípios e invariantes na janela temporal considerada (2007-2016), não requerem operacionalização, justamente por não terem se alterado. Demais fatores estruturais, com diferenciação entre localidades, são captados via modelo para dados em painel, que considera o agrupamento das observações (tomadas ao longo do tempo) em municípios aos quais elas pertencem. 0 teste de Hausman indica que um modelo com efeitos fixos de município $\left(a_{\mathrm{i}}\right)$ é preferível em relação à especificação com interceptos aleatórios por município ( $p$-valor = 0,0000). No modelo com efeitos fixos de município, um conjunto de dummies identificando cada município controla pelas diferenças entre essas unidades, desde que tais diferenças tenham permanecido constantes de 2007 a 2016, a exemplo do ano de criação e da condição de capital.

Condicionantes do desempenho fiscal que se modificam no tempo, porém atingindo igualmente todos os municípios, são operacionalizados por efeitos fixos de ano $\left(b_{t}\right)$. Exemplos de fatores dessa natureza são a situação fiscal da União e do Estado de Minas Gerais; também, especificamente em 2016, as receitas municipais aumentaram perto de 4\%, em média, como resultado da Lei de Repatriação (Lei Federal no 13.254/2016, sobre regularização de recursos de origem lícita), já que IR e multas apuradas na repatriação foram distribuídos aos municípios seguindo o esquema de repartição do FPM (SISTEMA FIRJAN, 2017a).

Ainda, o último ano do mandato é aquele em que tipicamente os municípios 
mais investem - em média, um investimento $20 \%$ maior que nos primeiros três anos de governo (SISTEMA FIRJAN, 2017a). Ademais, fatores institucionais também podem impor um comportamento cíclico ao desempenho fiscal, padrão esse absorvido por efeitos fixos de tempo. Por exemplo, a LRF (art. 42) requer que prefeitos em último ano de mandato deixem disponibilidade de caixa suficiente para honrar restos a pagar.

Já os fatores conjunturais singulares aos municípios requerem covariáveis específicas $\left(\boldsymbol{\beta} \mathbf{C}_{\mathrm{it} ;(\mathrm{t}-1)}\right)$. O Quadro 5 lista esses condicionantes, sua operacionalização, fontes de dados e sinais esperados. O legado fiscal é representado por cinco variáveis, informando o valor de cada um dos componentes do IFGF no ano anterior $(t-1)$. O contexto econômico é operacionalizado pelo PIB municipal per capita em $t-1$, ajustado para reais de dezembro de 2016 pelo Índice Nacional de Preços ao Consumidor. A população do município (em milhares de pessoas) no ano anterior representa a base da arrecadação, mas também informa a escala da demanda por serviços públicos. O Índice Firjan de Desenvolvimento Municipal (IFDM) defasado - em $t$-1 ou no último ano-base disponível quando da elaboração deste trabalho (i.e., 2013) - caracteriza a complexidade dessa demanda, ao considerar três dimensões de desenvolvimento: educação, emprego e renda, e saúde (SISTEMA FIRJAN, 2015); quanto maior o IFDM, melhor a situação do município. A capacidade de atração de outros recursos, como instalação de equipamentos públicos diretamente custeados pelas demais esferas, é caracterizada pela coincidência entre o partido pelo qual o chefe do Executivo municipal se elegeu e o partido dos Executivos federal e estadual. Cotas do FPM e transferências voluntárias (da União e do Estado de Minas Gerais) para as prefeituras são representadas pelo seu percentual em relação à receita total em $t$. 
Quadro 05 | Modelagem empírica: influências sobre desempenho fiscal, operacionalização, fontes e sinais esperados

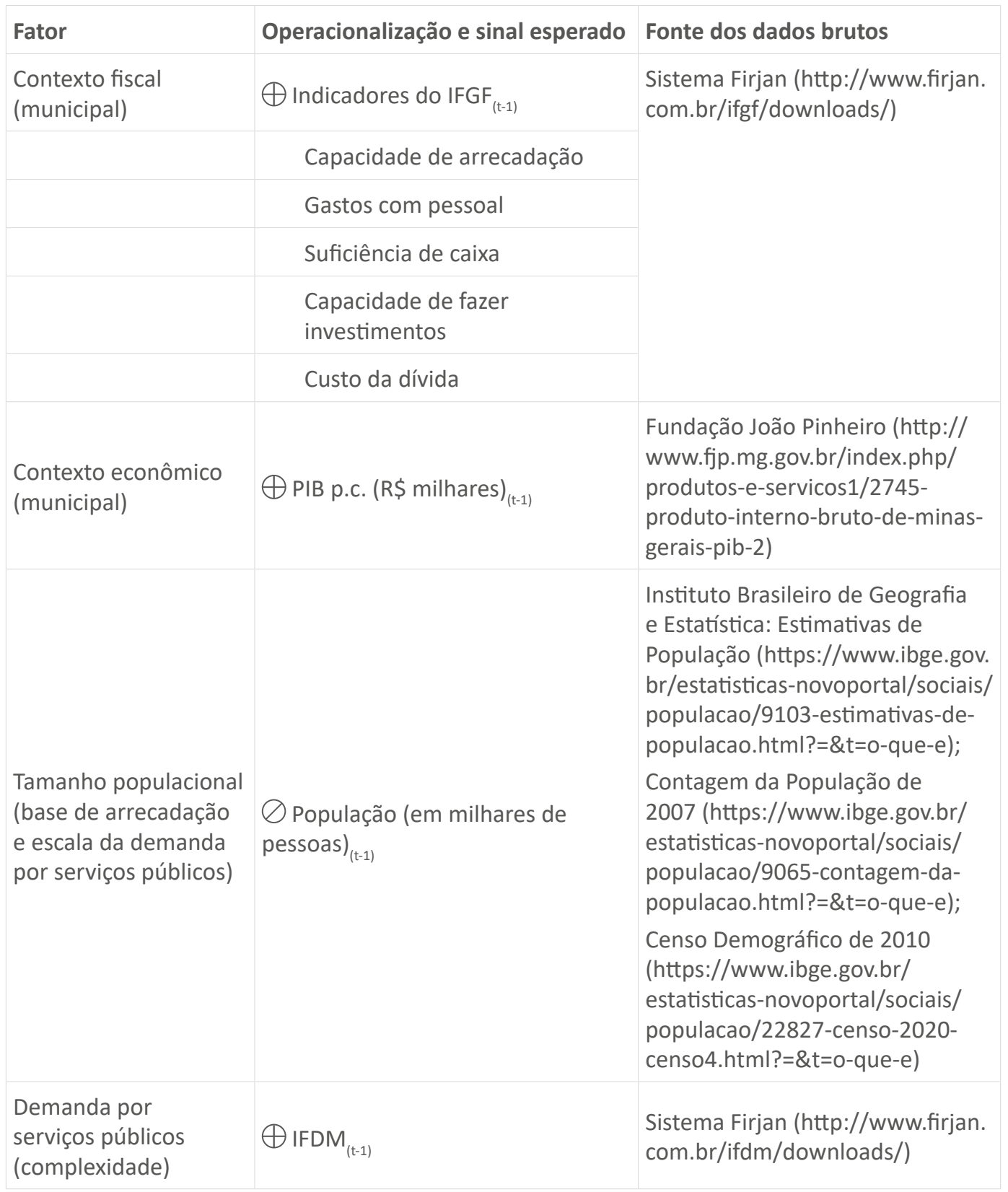




\begin{tabular}{|c|c|c|}
\hline Fator & Operacionalização e sinal esperado & Fonte dos dados brutos \\
\hline \multirow[t]{3}{*}{$\begin{array}{l}\text { Capacidade de atração } \\
\text { de recursos* }\end{array}$} & $\bigoplus$ Alinhamento partidário $_{\mathrm{t}}$ & \multirow{3}{*}{$\begin{array}{l}\text { Tribunal Superior Eleitoral } \\
\text { (http://www.tse.jus.br/eleicoes/ } \\
\text { estatisticas/repositorio-de-dados- } \\
\text { eleitorais) }\end{array}$} \\
\hline & Presidente & \\
\hline & Governador & \\
\hline \multirow[t]{4}{*}{$\begin{array}{l}\text { Transferências } \\
\text { intergovernamentais } \\
\text { (realizadas) }\end{array}$} & $\oslash$ Cota do FPM (\% das receitas) $_{\mathrm{t}}$ & \multirow{4}{*}{$\begin{array}{l}\text { Secretaria do Tesouro Nacional: } \\
\text { Finbra - Finanças do Brasil - } \\
\text { Dados Contábeis dos Municípios } \\
\text { (http://www.tesouro.fazenda.gov. } \\
\text { br/pt_PT/contas-anuais) }\end{array}$} \\
\hline & $\begin{array}{l}\oslash \text { Transferências voluntárias } \\
\text { (\% das receitas })_{t}\end{array}$ & \\
\hline & União & \\
\hline & Estado & \\
\hline Alternância ideológica & - & - \\
\hline Ano eleitoral & $\oslash$ Efeitos fixos de ano $_{\mathrm{t}}$ & - \\
\hline Fator & Operacionalização e sinal esperado & Fonte dos dados brutos \\
\hline \multirow[t]{2}{*}{$\begin{array}{l}\text { Probabilidade de } \\
\text { manutenção do } \\
\text { incumbente ou seu } \\
\text { grupo no poder }\end{array}$} & $\begin{array}{l}\oslash \text { Prefeito em segundo mandato } \\
\text { consecutivot }\end{array}$ & \multirow{2}{*}{$\begin{array}{l}\text { Tribunal Superior Eleitoral (http:// } \\
\text { www.tse.jus.br/eleitor-e-eleicoes/ } \\
\text { estatisticas/eleicoes/eleicoes- } \\
\text { anteriores/estatisticas-eleitorais- } \\
\text { anos-anteriores) }\end{array}$} \\
\hline & $\begin{array}{l}\oslash \text { Votos válidos recebidos pelo } \\
\text { prefeito }(\%)_{t}\end{array}$ & \\
\hline $\begin{array}{l}\text { Qualidade da gestão } \\
\text { fiscal }\end{array}$ & (N.a.) Resíduos da regressão & - \\
\hline
\end{tabular}


Quanto aos ciclos políticos, optou-se por não incluir variável específica à alternância ideológica, visto que as dummies para alinhamento partidário carregam também conteúdo dessa ordem. Filiação do prefeito ao Partido dos Trabalhadores (PT) entre 2007 e 2015 (quase toda a janela temporal observada) é retratada pela dummy de alinhamento partidário com o Executivo nacional. Da mesma forma o faz o indicador de alinhamento com o partido do governador em 2015 e 2016, quando Fernando Pimentel (PT) dirigia o estado. Pertencimento do prefeito ao Partido da Social Democracia Brasileira (PSDB) é informado pelo alinhamento partidário com o governador de 2007 a 2013. Entre abril e dezembro de 2014, Minas Gerais foi governada por Alberto Pinto Coelho Júnior, do então Partido Progressista (PP, hoje Progressistas), vice-governador que assumiu o governo com a renúncia de Antônio Anastasia (PSDB).

A condição de ano eleitoral é reportada pelos efeitos fixos de tempo (eleições gerais em 2010 e 2014, e municipais em 2008, 2012 e 2016). Finalmente, a probabilidade de manutenção do incumbente no poder é nula, caso a dummy indicando que o prefeito se encontra em segundo mandato consecutivo assuma valor um. O percentual de votos válidos recebidos pelo prefeito (dominância) é proxy do apoio em seu favor (ou em favor de candidatos por ele endossados) no próximo pleito. Foram descartadas observações (município-ano) para as quais houve eleições municipais suplementares desde o último ano de eleições locais (2004, 2008 ou 2012).

Quando direcionais, hipóteses para as relações com o desempenho fiscal são positivas. No caso do porte populacional, por representar a base arrecadatória e a escala da demanda por serviços públicos, dois fatores com influências potencialmente opostas sobre o desempenho fiscal, não há hipótese direcional definida. Além disso, não se propõe expectativa direcional para as transferências do FPM e as voluntárias em razão das associações esperadas com os componentes do IFGF, às vezes positivas, outras vezes negativas - nem para os fatores atinentes à probabilidade de manutenção do incumbente ou seu grupo no poder, pelo mesmo motivo.

Dada a dificuldade de apreensão da relação entre qualidade da gestão fiscal e desempenho fiscal, a análise dessa associação passa pelo exame dos resíduos da regressão, sendo tomados aqui como proxy para a qualidade da gestão fiscal. Essa estratégia de identificação baseada nos resíduos já foi empregada em diferentes contextos de pesquisa. Suri et al. (2011) utilizam os resíduos de uma regressão de Mínimos Quadrados Ordinários 
(MQO) da variação do desenvolvimento humano em função do crescimento econômico anterior como proxy para a parte da flutuação da primeira que não pode ser atribuída ao segundo. Por sua vez, Soares e Alves (2013) dimensionam os efeitos das escolas e dos municípios no desempenho dos estudantes do 5 ㅇ e 9 ㅇ anos do ensino fundamental a partir dos resíduos de modelos hierárquicos, com interceptos aleatórios. No presente trabalho, os resíduos são inspecionados de diferentes formas: correlações, diferença entre médias e testes de dependência espacial. Com essa combinação de abordagens, exploram-se potenciais padrões na distribuição da qualidade da gestão fiscal.

A Figura 1 mapeia a média do IFGF dos municípios mineiros entre 2007 e $2016^{11}$ e apresenta as regiões intermediárias do estado (13 no total). Regiões intermediárias correspondem a uma divisão territorial lançada pelo Instituto Brasileiro de Geografia e Estatística em 2017, em lugar das mesorregiões. Diferentemente destas, as regiões intermediárias recebem o nome de cidades-polo, abrangendo municípios sob a influência das últimas (e.g., no que tange ao fluxo de pessoas).

Figura 01 | Mapa dos municípios mineiros segundo o IFGF médio (2007-2016)

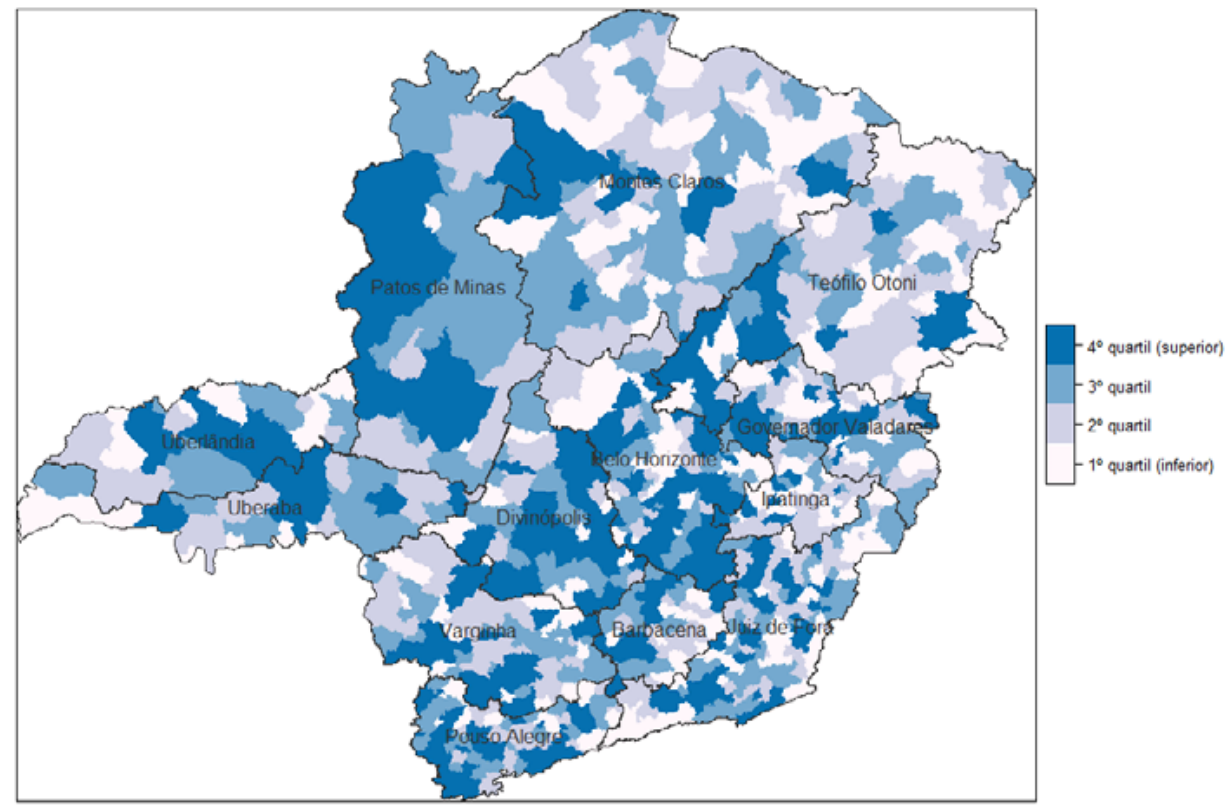

Fonte: elaboração própria.

Médias e outras estatísticas descritivas de variáveis selecionadas são apresentadas 
na Tabela 1, considerando-se as 7.633 observações com dados completos para a regressão. Os indicadores concernentes ao IFGF e IFDM apresentam-se na escala 0-100. Nota-se que receita própria é a dimensão do IFGF com menores escores (média $=23$ ), enquanto o custo da dívida alcança média superior a 80. O PIB per capita ${ }_{(\mathrm{t}-1)}$ mostrou grande dispersão, com valores mínimo e máximo de R\$ 3,42 mil (em São João das Missões, na região de Montes Claros) e R\$ 421,98 mil (em São Gonçalo do Rio Abaixo, na região de Ipatinga). Em $17 \%$ das observações, o prefeito era do mesmo partido do governador, e em $28 \%$ delas o prefeito estava em seu segundo mandato consecutivo.

Tabela 01 | Estatísticas descritivas de variáveis selecionadas

\begin{tabular}{|c|c|c|c|c|}
\hline Variável & Média & $\begin{array}{l}\text { Desvio } \\
\text { padrão }\end{array}$ & Mínimo & Máximo \\
\hline IFGF Geral ${ }_{t}$ & 48,66 & 12,68 & 10,68 & 99,31 \\
\hline IFGF Receita própria ${ }_{t}$ & 22,91 & 16,98 & 0,00 & 100,00 \\
\hline IFGF Rigidez orçamentária ${ }_{t}$ & 57,04 & 16,05 & 0,00 & 100,00 \\
\hline IFGF Liquidez ${ }_{t}$ & 46,09 & 34,00 & 0,00 & 100,00 \\
\hline IFGF Investimentos $_{t}$ & 54,37 & 27,07 & 0,00 & 100,00 \\
\hline IFGF Custo da dívida ${ }_{t}$ & 80,66 & 14,15 & 0,00 & 100,00 \\
\hline IFGF Geral $_{(\mathrm{t}-1)}$ & 49,06 & 12,81 & 10,68 & 99,31 \\
\hline IFGF Receita própria $_{(\mathrm{t}-1)}$ & 22,90 & 17,01 & 0,00 & 100,00 \\
\hline IFGF Rigidez orçamentária $_{(\mathrm{t}-1)}$ & 57,79 & 16,06 & 0,00 & 100,00 \\
\hline IFGF Liquidez $_{(t-1)}$ & 44,59 & 34,26 & 0,00 & 100,00 \\
\hline IFGF Investimentos $_{(\mathrm{t}-1)}$ & 56,97 & 26,70 & 0,00 & 100,00 \\
\hline IFGF Custo da dívida $_{(t-1)}$ & 80,50 & 14,14 & 0,00 & 100,00 \\
\hline PIB p.c. (R\$ milhares) $)_{(t-1)}$ & 16,66 & 18,18 & 3,42 & 421,98 \\
\hline Variação \% PIB p.c. ${ }_{(t-2, t-1)}$ & 5,49 & 20,37 & $-83,67$ & 465,23 \\
\hline População (milhares de pessoas) $(\mathrm{t}-1)$ & 24,47 & 100,79 & 0,81 & $2.502,56$ \\
\hline IFDM $_{t}$ & 64,45 & 9,13 & 28,66 & 90,50 \\
\hline $\operatorname{IFDM}_{(\mathrm{t}-1)}$ & 63,41 & 9,52 & 29,01 & 90,50 \\
\hline Prefeito do mesmo partido do presidente ${ }_{t}$ & 0,13 & 0,33 & 0,00 & 1,00 \\
\hline
\end{tabular}




\begin{tabular}{|c|c|c|c|c|}
\hline Variável & Média & $\begin{array}{l}\text { Desvio } \\
\text { padrão }\end{array}$ & Mínimo & Máximo \\
\hline Prefeito do mesmo partido do governador ${ }_{t}$ & 0,17 & 0,37 & 0,00 & 1,00 \\
\hline Cota do FPM (\% das receitas) ${ }_{t}$ & 38,38 & 13,04 & 0,00 & 100,00 \\
\hline $\begin{array}{l}\text { Transferências voluntárias da União } \\
\text { (\% das receitas) }\end{array}$ & 2,26 & 2,99 & 0,00 & 36,32 \\
\hline $\begin{array}{l}\text { Transferências voluntárias do estado } \\
\text { (\% das receitas) }\end{array}$ & 2,60 & 2,78 & 0,00 & 28,13 \\
\hline Prefeito em segundo mandato consecutivo ${ }_{t}$ & 0,28 & 0,45 & 0,00 & 1,00 \\
\hline Votos válidos recebidos pelo prefeito $(\%)_{t}$ & 55,77 & 12,05 & 24,22 & 100,00 \\
\hline \multicolumn{5}{|l|}{ Votos válidos recebidos pelo prefeito $(\%)_{t}{ }^{*}$} \\
\hline Prefeito em segundo mandato consecutivo ${ }_{t}$ & 16,58 & 27,58 & 0,00 & 100,00 \\
\hline$t=2007$ & 0,10 & 0,31 & 0,00 & 1,00 \\
\hline$t=2008$ & 0,11 & 0,31 & 0,00 & 1,00 \\
\hline$t=2009$ & 0,10 & 0,31 & 0,00 & 1,00 \\
\hline$t=2010$ & 0,11 & 0,31 & 0,00 & 1,00 \\
\hline$t=2011$ & 0,10 & 0,31 & 0,00 & 1,00 \\
\hline$t=2012$ & 0,10 & 0,30 & 0,00 & 1,00 \\
\hline$t=2013$ & 0,10 & 0,30 & 0,00 & 1,00 \\
\hline$t=2014$ & 0,09 & 0,29 & 0,00 & 1,00 \\
\hline$t=2015$ & 0,10 & 0,29 & 0,00 & 1,00 \\
\hline$t=2016$ & 0,09 & 0,29 & 0,00 & 1,00 \\
\hline
\end{tabular}

Nota: valores de IFGF e IFDM apresentam-se na escala 0-100. Observações $=7.633$, exceto para o IFDM t' $^{\prime}$ com 7.621 observações.

Fonte: elaboração própria.

Ainda, interessa analisar a sensibilidade dos componentes do IFGF aos fatores explicativos elencados. De acordo com o modelo conceitual, a expectativa é que nem todos os componentes do IFGF reajam na mesma direção a uma variação nos fatores explicativos. Por exemplo, tudo o mais constante e na ausência de flypaper effect, transferências intergovernamentais reduzem o percentual da RCL despendido com pessoal (melhorando o respectivo componente do IFGF), porém deprimem o indicador de receitas próprias. A estimação de regressões tendo como variável dependente cada componente do IFGF 
possibilita examinar, em maior nível de granularidade, em que medida o modelo conceitual encontra amparo empírico.

Enquanto na amostra de trabalho os valores mínimo e máximo do IFGF são 10,68 e 99,31, os componentes do IFGF são censurados nos extremos da escala (0 e 100), como mostra a Tabela 1. Essa condição implica que o processo de MQO produziria estimadores inconsistentes de tais componentes. Aqui, pode-se pensar em uma variável latente irrestrita, geradora da variável da qual se observa apenas uma versão censurada, em um ou ambos os extremos. Modelos tobit longitudinais são adequados para analisar dados de painel assim truncados (TWISK; RIJMEN, 2009). A intuição por trás da regressão tobit é modelar a probabilidade que $\mathbf{y}_{\text {it }}$ alcance o valor piso ou teto, e prever os valores de $\mathbf{y}_{i t^{\prime}}$ no intervalo não censurado. Essa formulação não acomoda efeitos fixos de município e foi calculada com interceptos aleatórios por município.

\section{Resultados}

Coeficientes e outros atributos das especificações estimadas via modelo de regressão são apresentados na Tabela 2. A especificação (1), apenas com efeitos fixos cross section (ao nível do município), explica mais de $50 \%$ da variação do IFGF $_{t}$ em torno de sua média, sugerindo expressiva presença de singularidades locais constantes no tempo na determinação do desempenho fiscal. Alternativamente, esse resultado poderia indicar que o IFGF pouco varia longitudinalmente. Efeitos fixos de ano (2) produzem diversos coeficientes estatisticamente significantes e robustos à inclusão de covariáveis; as estimativas sugerem uma deterioração do desempenho fiscal em 2009 em relação a 2007, e de 2012 até 2016, sendo 2015 o ano com menores valores médios do IFGF, provavelmente um reflexo da recessão econômica (queda de 3,8\% do PIB nacional em 2015, a maior no intervalo considerado).

Com exceção do indicador de investimentos, os componentes defasados do IFGF retornam parâmetros positivos (conforme expectativa), estatisticamente significantes e de magnitudes, em sua maior parte, relativamente estáveis nas especificações (3) a (8). 
Associações captadas em ( 3$)^{12}$ são modestas, todavia; as estimativas de maior monta, referentes às dimensões receita própria ${ }_{(\mathrm{t}-1)}$ e liquidez ${ }_{(\mathrm{t}-1)}$, indicam que um aumento de um ponto nessas covariáveis (apresentadas na escala 0-100) associa-se com uma elevação da ordem de 0,1 no IFGF (também em escala 0-100).

As duas medidas da base arrecadatória (PIB municipal e o tamanho populacional), bem como o IFDM, não apresentam significância estatística. Alinhamento partidário com o chefe do Executivo estadual perde significância quando as transferências voluntárias são

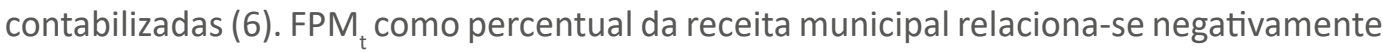
com o IFGF : para cada elevação de um ponto, o indicador de gestão fiscal tende a declinar em aproximadamente meio ponto. Ainda, as estimativas sugerem que o efeito das transferências intergovernamentais é condicional ao tipo de transferência, haja vista a relação positiva entre o IFGF e repasses voluntários. Um aumento de um ponto percentual nas transferências discricionárias da União ou do estado associa-se com uma elevação na faixa de 0,5 a 0,6 ponto no IFGF, tudo o mais constante - conforme (8), a especificação principal. 


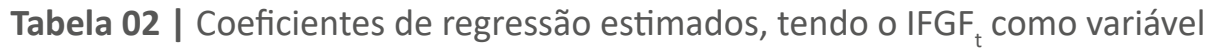
dependente

\begin{tabular}{|c|c|c|c|c|c|c|c|c|c|c|c|}
\hline \multirow[b]{2}{*}{$\begin{array}{l}\text { Variável inde- } \\
\text { pendente }\end{array}$} & \multicolumn{11}{|c|}{ Especificação } \\
\hline & (1) & $(2)$ & (3) & (4) & (5) & (6) & (7) & (8) & (9) & (10) & (11) \\
\hline $\begin{array}{l}\text { IFGF Receita } \\
\text { própria }_{(\mathrm{t}-1)}\end{array}$ & & & $\begin{array}{c}0,111^{* * *} \\
(0,025)\end{array}$ & $\begin{array}{c}0,111^{* * *} \\
(0,025)\end{array}$ & $\begin{array}{c}0,112 * * * \\
(0,025)\end{array}$ & $\begin{array}{c}0,064 * * * \\
(0,019)\end{array}$ & $\begin{array}{c}0,064 * * * \\
(0,018)\end{array}$ & $\begin{array}{c}0,064 * * * \\
(0,018)\end{array}$ & $\begin{array}{c}0,170 * * * \\
(0,011)\end{array}$ & $\begin{array}{l}0,073^{*} \\
(0,038)\end{array}$ & $\begin{array}{c}0,064 * * * \\
(0,022)\end{array}$ \\
\hline $\begin{array}{l}\text { IFGF Rigidez } \\
\text { orçamentária }_{(t-1)}\end{array}$ & & & $\begin{array}{c}0,063^{* * *} \\
(0,009)\end{array}$ & $\begin{array}{c}0,063^{* * *} \\
(0,009)\end{array}$ & $\begin{array}{c}0,063^{* * *} \\
(0,009)\end{array}$ & $\begin{array}{c}0,057^{* * *} \\
(0,008)\end{array}$ & $\begin{array}{c}0,056 * * * \\
(0,008)\end{array}$ & $\begin{array}{c}0,056 * * * \\
(0,008)\end{array}$ & $\begin{array}{c}0,134 * * * \\
(0,007)\end{array}$ & $\begin{array}{c}0,095 * * * \\
(0,018)\end{array}$ & $\begin{array}{c}0,053 * * * \\
(0,008)\end{array}$ \\
\hline IFGF Liquidez $_{(\mathrm{t}-1)}$ & & & $\begin{array}{c}0,110 * * * \\
(0,005)\end{array}$ & $\begin{array}{c}0,110 * * * \\
(0,005)\end{array}$ & $\begin{array}{c}0,110 * * * \\
(0,005)\end{array}$ & $\begin{array}{c}0,111^{* * *} \\
(0,005)\end{array}$ & $\begin{array}{c}0,110 * * * \\
(0,005)\end{array}$ & $\begin{array}{c}0,110^{* * *} \\
(0,005)\end{array}$ & $\begin{array}{c}0,180 * * * \\
(0,003)\end{array}$ & $\begin{array}{c}0,129 * * * \\
(0,008)\end{array}$ & $\begin{array}{c}0,108 * * * \\
(0,006)\end{array}$ \\
\hline $\begin{array}{l}\text { IFGF Investimen- } \\
\text { tos }_{(\mathrm{t}-1)}\end{array}$ & & & $\begin{array}{c}0,016 * * * \\
(0,005)\end{array}$ & $\begin{array}{c}0,016 * * * \\
(0,005)\end{array}$ & $\begin{array}{c}0,016 * * * \\
(0,005)\end{array}$ & $\begin{array}{c}0,004 \\
(0,005)\end{array}$ & $\begin{array}{c}0,004 \\
(0,004)\end{array}$ & $\begin{array}{c}0,004 \\
(0,004)\end{array}$ & $\begin{array}{c}0,056 * * * \\
(0,004)\end{array}$ & $\begin{array}{c}0,044^{* * *} \\
(0,009)\end{array}$ & $\begin{array}{l}-0,003 \\
(0,005)\end{array}$ \\
\hline $\begin{array}{l}\text { IFGF Custo da } \\
\text { dívida }_{(t-1)}\end{array}$ & & & $\begin{array}{c}0,067 * * * \\
(0,011)\end{array}$ & $\begin{array}{c}0,067^{* * *} \\
(0,011)\end{array}$ & $\begin{array}{c}0,067 * * * \\
(0,011)\end{array}$ & $\begin{array}{c}0,072 * * * \\
(0,010)\end{array}$ & $\begin{array}{c}0,072 * * * \\
(0,010)\end{array}$ & $\begin{array}{c}0,072 * * * \\
(0,010)\end{array}$ & $\begin{array}{c}0,105^{* * *} \\
(0,008)\end{array}$ & $\begin{array}{c}0,075 * * * \\
(0,021)\end{array}$ & $\begin{array}{c}0,069 * * * \\
(0,011)\end{array}$ \\
\hline $\begin{array}{l}\text { PIB p.c. (R\$ } \\
\text { milhares) }\end{array}$ & & & & $\begin{array}{c}0,019 \\
(0,014)\end{array}$ & $\begin{array}{c}0,018 \\
(0,014)\end{array}$ & $\begin{array}{c}0,009 \\
(0,014)\end{array}$ & $\begin{array}{c}0,009 \\
(0,013)\end{array}$ & $\begin{array}{c}0,009 \\
(0,014)\end{array}$ & $\begin{array}{c}0,013 \\
(0,009)\end{array}$ & $\begin{array}{l}0,046 * \\
(0,024)\end{array}$ & $\begin{array}{c}0,006 \\
(0,014)\end{array}$ \\
\hline $\begin{array}{l}\text { População } \\
\text { (milhares de } \\
\text { pessoas) }_{(\mathrm{t}-1)}\end{array}$ & & & & $\begin{array}{l}-0,048 \\
(0,044)\end{array}$ & $\begin{array}{l}-0,050 \\
(0,045)\end{array}$ & $\begin{array}{l}-0,035 \\
(0,041)\end{array}$ & $\begin{array}{l}-0,036 \\
(0,040)\end{array}$ & $\begin{array}{l}-0,036 \\
(0,040)\end{array}$ & $\begin{array}{c}0,001 \\
(0,003)\end{array}$ & $\begin{array}{l}-0,090 \\
(0,091)\end{array}$ & $\begin{array}{c}0,021 \\
(0,032)\end{array}$ \\
\hline $\operatorname{IFDM}_{(\mathrm{t}-1)}$ & & & & $\begin{array}{c}0,013 \\
(0,034)\end{array}$ & $\begin{array}{c}0,012 \\
(0,034)\end{array}$ & $\begin{array}{l}-0,021 \\
(0,031)\end{array}$ & $\begin{array}{l}-0,024 \\
(0,032)\end{array}$ & $\begin{array}{l}-0,024 \\
(0,032)\end{array}$ & $\begin{array}{c}0,081^{* * *} \\
(0,014)\end{array}$ & $\begin{array}{l}-0,012 \\
(0,050)\end{array}$ & $\begin{array}{l}-0,016 \\
(0,032)\end{array}$ \\
\hline $\begin{array}{l}\text { Prefeito do } \\
\text { mesmo partido } \\
\text { do presidente }\end{array}$ & & & & & $\begin{array}{l}-0,280 \\
(0,372)\end{array}$ & $\begin{array}{l}-0,145 \\
(0,369)\end{array}$ & $\begin{array}{l}-0,133 \\
(0,364)\end{array}$ & $\begin{array}{l}-0,135 \\
(0,366)\end{array}$ & $\begin{array}{c}0,513^{* *} \\
(0,233)\end{array}$ & $\begin{array}{l}-0,098 \\
(0,541)\end{array}$ & $\begin{array}{l}-0,314 \\
(0,423)\end{array}$ \\
\hline $\begin{array}{l}\text { Prefeito do } \\
\text { mesmo partido } \\
\text { do governador }\end{array}$ & & & & & $\begin{array}{c}0,854 * * \\
(0,350)\end{array}$ & $\begin{array}{l}0,586^{*} \\
(0,350)\end{array}$ & $\begin{array}{c}0,573 \\
(0,351)\end{array}$ & $\begin{array}{c}0,573 \\
(0,352)\end{array}$ & $\begin{array}{l}0,483^{*} \\
(0,262)\end{array}$ & $\begin{array}{l}1,105 * * \\
(0,547)\end{array}$ & $\begin{array}{c}0,500 \\
(0,368)\end{array}$ \\
\hline $\begin{array}{l}\text { Cota do FPM (\% } \\
\text { das receitas) }\end{array}$ & & & & & & $\begin{array}{c}-0,477 * * * \\
(0,048)\end{array}$ & $\begin{array}{c}-0,477 * * * \\
(0,048)\end{array}$ & $\begin{array}{c}-0,477 * * * \\
(0,048)\end{array}$ & $\begin{array}{c}-0,087 * * * \\
(0,014)\end{array}$ & $\begin{array}{c}-0,352 * * * \\
(0,101)\end{array}$ & $\begin{array}{c}-0,526 * * * \\
(0,054)\end{array}$ \\
\hline $\begin{array}{l}\text { Transferências } \\
\text { voluntárias do } \\
\text { estado (\% das } \\
\text { receitas) }\end{array}$ & & & & & & $\begin{array}{c}0,514 * * * \\
(0,037)\end{array}$ & $\begin{array}{c}0,516 * * * \\
(0,037)\end{array}$ & $\begin{array}{c}0,516 * * * \\
(0,037)\end{array}$ & $\begin{array}{c}0,614^{* * *} \\
(0,037)\end{array}$ & $\begin{array}{c}0,605^{* * *} \\
(0,087)\end{array}$ & $\begin{array}{c}0,500 * * * \\
(0,038)\end{array}$ \\
\hline $\begin{array}{l}\text { Prefeito em se- } \\
\text { gundo mandato } \\
\text { consecutivo }_{t}\end{array}$ & & & & & & & $\begin{array}{l}0,445^{*} \\
(0,269)\end{array}$ & $\begin{array}{l}-0,085 \\
(1,502)\end{array}$ & $\begin{array}{l}-0,585 \\
(1,144)\end{array}$ & $\begin{array}{c}4,309 * * \\
(1,814)\end{array}$ & $\begin{array}{l}-0,280 \\
(1,552)\end{array}$ \\
\hline $\begin{array}{l}\text { Votos válidos } \\
\text { recebidos pelo } \\
\text { prefeito }(\%)_{t}\end{array}$ & & & & & & & $\begin{array}{c}0,000 \\
(0,014)\end{array}$ & $\begin{array}{l}-0,003 \\
(0,021)\end{array}$ & $\begin{array}{l}-0,003 \\
(0,012)\end{array}$ & $\begin{array}{c}0,018 \\
(0,025)\end{array}$ & $\begin{array}{l}-0,005 \\
(0,021)\end{array}$ \\
\hline $\begin{array}{l}\text { Votos válidos } \\
\text { recebidos pelo } \\
\text { prefeito }(\%)_{t}^{*}\end{array}$ & & & & & & & & 0,009 & 0,016 & $-0,080 * *$ & 0,015 \\
\hline $\begin{array}{l}\text { Prefeito em se- } \\
\text { gundo mandato } \\
\text { consecutivo }_{t}\end{array}$ & & & & & & & & $(0,026)$ & $(0,020)$ & $(0,031)$ & $(0,027)$ \\
\hline
\end{tabular}


Especificação

\begin{tabular}{|c|c|c|c|c|c|c|c|c|c|c|c|}
\hline $\begin{array}{l}\text { Variável inde- } \\
\text { pendente }\end{array}$ & (1) & (2) & (3) & (4) & (5) & (6) & (7) & (8) & (9) & (10) & (11) \\
\hline$t=2008$ & & $\begin{array}{c}5,088 * * * \\
(0,729)\end{array}$ & $\begin{array}{c}4,801^{* * *} \\
(0,348)\end{array}$ & $\begin{array}{c}4,755^{* * *} \\
(0,361)\end{array}$ & $\begin{array}{c}4,754 * * * \\
(0,361)\end{array}$ & $\begin{array}{c}3,849 * * * \\
(0,325)\end{array}$ & $\begin{array}{c}3,851 * * * \\
(0,325)\end{array}$ & $\begin{array}{c}3,851 * * * \\
(0,325)\end{array}$ & $\begin{array}{c}3,567 * * * \\
(0,362)\end{array}$ & & $\begin{array}{c}3,837 * * * \\
(0,317)\end{array}$ \\
\hline$t=2009$ & & $\begin{array}{c}-3,077 * * * \\
(0,744)\end{array}$ & $\begin{array}{c}-4,764 * * * \\
(0,356)\end{array}$ & $\begin{array}{c}-4,783 * * * \\
(0,358)\end{array}$ & $\begin{array}{c}-4,779 * * * \\
(0,355)\end{array}$ & $\begin{array}{c}-4,930 * * * \\
(0,330)\end{array}$ & $\begin{array}{c}-5,015^{* * *} \\
(0,341)\end{array}$ & $\begin{array}{c}-5,021 * * * \\
(0,339)\end{array}$ & $\begin{array}{c}-5,906 * * * \\
(0,354)\end{array}$ & & $\begin{array}{c}-5,053 * * * \\
(0,348)\end{array}$ \\
\hline$t=2010$ & & $\begin{array}{c}2,718 * * * \\
(0,647)\end{array}$ & $\begin{array}{c}2,489 * * * \\
(0,330)\end{array}$ & $\begin{array}{c}2,459 * * * \\
(0,341)\end{array}$ & $\begin{array}{c}2,457 * * * \\
(0,347)\end{array}$ & $\begin{array}{c}-1,168^{* * *} \\
(0,390)\end{array}$ & $\begin{array}{c}-1,270 * * * \\
(0,395)\end{array}$ & $\begin{array}{c}-1,277 * * * \\
(0,391)\end{array}$ & $\begin{array}{c}0,976^{* *} \\
(0,402)\end{array}$ & & $\begin{array}{c}-1,671 * * * \\
(0,438)\end{array}$ \\
\hline$t=2011$ & & $\begin{array}{c}2,644 * * * \\
(0,727)\end{array}$ & $\begin{array}{c}1,384 * * * \\
(0,371)\end{array}$ & $\begin{array}{c}1,259 * * * \\
(0,430)\end{array}$ & $\begin{array}{c}1,261^{* * *} \\
(0,435)\end{array}$ & $\begin{array}{c}0,512 \\
(0,449)\end{array}$ & $\begin{array}{c}0,428 \\
(0,447)\end{array}$ & $\begin{array}{c}0,422 \\
(0,448)\end{array}$ & $\begin{array}{l}-0,068 \\
(0,386)\end{array}$ & & $\begin{array}{c}0,309 \\
(0,470)\end{array}$ \\
\hline$t=2012$ & & $\begin{array}{c}0,145 \\
(0,654)\end{array}$ & $\begin{array}{c}-1,260 * * * \\
(0,369)\end{array}$ & $\begin{array}{c}-1,437 * * * \\
(0,389)\end{array}$ & $\begin{array}{c}-1,428 * * * \\
(0,393)\end{array}$ & $\begin{array}{c}-4,315^{* * *} \\
(0,420)\end{array}$ & $\begin{array}{c}-4,393 * * * \\
(0,414)\end{array}$ & $\begin{array}{c}-4,399 * * * \\
(0,415)\end{array}$ & $\begin{array}{c}-4,151 * * * \\
(0,341)\end{array}$ & $\begin{array}{c}-7,882 * * * \\
(0,678)\end{array}$ & $\begin{array}{c}-4,652 * * * \\
(0,437)\end{array}$ \\
\hline$t=2013$ & & $\begin{array}{c}-5,586 * * * \\
(0,659)\end{array}$ & $\begin{array}{c}-5,842 * * * \\
(0,380)\end{array}$ & $\begin{array}{c}-6,035 * * * \\
(0,474)\end{array}$ & $\begin{array}{c}-6,011^{* * *} \\
(0,480)\end{array}$ & $\begin{array}{c}-6,777^{* * *} \\
(0,520)\end{array}$ & $\begin{array}{c}-6,751 * * * \\
(0,520)\end{array}$ & $\begin{array}{c}-6,747 * * * \\
(0,523)\end{array}$ & $\begin{array}{c}-5,957 * * * \\
(0,416)\end{array}$ & & $\begin{array}{c}-6,997 * * * \\
(0,538)\end{array}$ \\
\hline$t=2014$ & & $\begin{array}{c}-1,916 * * * \\
(0,660)\end{array}$ & $\begin{array}{c}-1,635 * * * \\
(0,323)\end{array}$ & $\begin{array}{c}-1,791 * * * \\
(0,459)\end{array}$ & $\begin{array}{c}-1,769 * * * \\
(0,465)\end{array}$ & $\begin{array}{c}-4,938^{* * *} \\
(0,555)\end{array}$ & $\begin{array}{c}-4,924 * * * \\
(0,553)\end{array}$ & $\begin{array}{c}-4,921 * * * \\
(0,556)\end{array}$ & $\begin{array}{c}-2,352^{* * *} \\
(0,374)\end{array}$ & & $\begin{array}{c}-5,436^{* * *} \\
(0,585)\end{array}$ \\
\hline$t=2015$ & & $\begin{array}{c}-7,296 * * * \\
(0,735)\end{array}$ & $\begin{array}{c}-7,332 * * * \\
(0,397)\end{array}$ & $\begin{array}{c}-7,483 * * * \\
(0,493)\end{array}$ & $\begin{array}{c}-7,436 * * * \\
(0,501)\end{array}$ & $\begin{array}{c}-8,194 * * * \\
(0,533)\end{array}$ & $\begin{array}{c}-8,169 * * * \\
(0,530)\end{array}$ & $\begin{array}{c}-8,166 * * * \\
(0,533)\end{array}$ & $\begin{array}{c}-7,329 * * * \\
(0,446)\end{array}$ & & $\begin{array}{c}-8,480 * * * \\
(0,550)\end{array}$ \\
\hline$t=2016$ & & $\begin{array}{c}-3,075^{* * *} \\
(0,600)\end{array}$ & $\begin{array}{c}-1,947 * * * \\
(0,406)\end{array}$ & $\begin{array}{c}-2,061^{* * *} \\
(0,453)\end{array}$ & $\begin{array}{c}-2,010 * * * \\
(0,456)\end{array}$ & $\begin{array}{c}-2,544 * * * \\
(0,472)\end{array}$ & $\begin{array}{c}-2,531 * * * \\
(0,470)\end{array}$ & $\begin{array}{c}-2,528 * * * \\
(0,472)\end{array}$ & $\begin{array}{c}-0,406 \\
(0,385)\end{array}$ & $\begin{array}{c}-4,966 * * * \\
(0,785)\end{array}$ & \\
\hline Constante & $\begin{array}{c}48,658^{* * *} \\
(0,273)\end{array}$ & $\begin{array}{c}49,547 * * * \\
(0,536)\end{array}$ & $\begin{array}{c}32,566 * * * \\
(1,151)\end{array}$ & $\begin{array}{c}32,742 * * * \\
(2,607)\end{array}$ & $\begin{array}{c}32,749 * * * \\
(2,604)\end{array}$ & $\begin{array}{c}53,261 * * * \\
(2,792)\end{array}$ & $\begin{array}{c}53,433 * * * \\
(2,876)\end{array}$ & $\begin{array}{c}53,641 * * * \\
(2,875)\end{array}$ & $\begin{array}{c}14,137^{* * *} \\
(1,490)\end{array}$ & $\begin{array}{c}45,259 * * * \\
(6,363)\end{array}$ & $\begin{array}{c}55,088 * * * \\
(3,070)\end{array}$ \\
\hline Observações & 7.633 & 7.633 & 7.633 & 7.633 & 7.633 & 7.633 & 7.633 & 7.633 & 7.633 & 2.277 & 6.940 \\
\hline $\mathrm{R}^{2}$ & 0,514 & 0,086 & 0,652 & 0,652 & 0,652 & 0,701 & 0,701 & 0,701 & & 0,778 & 0,716 \\
\hline $\mathrm{R}^{2}$ ajustado & 0,453 & 0,0848 & 0,607 & 0,607 & 0,608 & 0,662 & 0,662 & 0,662 & & 0,642 & 0,675 \\
\hline $\begin{array}{l}\text { Efeitos fixos de } \\
\text { município }\end{array}$ & Sim & & Sim & Sim & Sim & Sim & Sim & Sim & & Sim & Sim \\
\hline $\begin{array}{l}\text { Efeitos fixos de } \\
\text { ano }\end{array}$ & & Sim & Sim & Sim & Sim & Sim & Sim & Sim & Sim & Sim & Sim \\
\hline
\end{tabular}

Interceptos

aleatórios por

$\operatorname{Sim}$

município

Notas: valores de IFGF e IFDM apresentam-se na escala 0-100. Variance Infation Factor (VIF) médio = 3,37 na especificação (8), que apresenta VIF máximo $=23,88$, impulsionado pela alta correção entre o percentual de votos válidos e a interação com prefeito em segundo mandato consecutivo; em (7), VIFs médio e máximo são de 1,63 e 2,80. Erros padrão agrupados por município são apresentados entre parênteses. ${ }^{* * *} \mathrm{p}<0,01, * * \mathrm{p}<0,05, * \mathrm{p}<0,10$.

Fonte: elaboração própria.

Nas especificações (9) e seguintes são experimentadas modificações do modelo principal. Efeitos fixos de município são substituídos por interceptos aleatórios por município em (9), retornando estimativas em geral mais positivas que as produzidas 
em (8). A especificação (10) corresponde ao modelo principal aplicado à subamostra ( $n=2.277)$ dos anos de eleição municipal (2008, 2012 e 2016); na maioria das vezes, também produz coeficientes mais positivos que os de (8). Alinhamento com o partido do governador, prefeito em segundo mandato consecutivo e a interação entre segundo mandato e dominância eleitoral revelam significância estatística. Portanto, a evidência indica que as variáveis políticas parecem ser mais salientes em anos de eleição local, como era de se esperar.

Em (11) são descartadas as 693 observações relativas a 2016; assim, a dummy para prefeito do mesmo partido do presidente significa também que o prefeito era filiado ao PT, quando eleito. Esse foi o caso de 12,61\% das 6.940 observações consideradas. Especificação (11) retorna estimativas bastante próximas às de (8), e não altera a significância estatística dos coeficientes.

A Tabela A1 (Apêndice) mostra resultados dos modelos tobit, tendo como variável dependente cada componente do IFGF; essas especificações permitem analisar a sensibilidade desses indicadores às variáveis explicativas. Coeficientes estimados evidenciam certo grau de persistência temporal dos componentes do IFGF; cada ponto adicional em liquidez ${ }_{(\mathrm{t}-1)}$, custo da dívida ${ }_{(\mathrm{t}-1)}$ e receitas próprias ${ }_{(\mathrm{t}-1)}$ associase com um incremento de 0,79, 0,74 e 0,60 na respectiva variável em $t$. Rigidez orçamentária e custo da dívida parecem reagir positivamente ao PIB per capita ${ }_{(\mathrm{t}-1)}$.

A complexidade da demanda por serviços públicos, medida pelo IFDM $(\mathrm{t}-1)$, relacionase positivamente com receitas próprias, liquidez e investimentos, e negativamente com as despesas de pessoal (i.e., rigidez orçamentária). Duas explicações plausíveis e complementares dizem respeito: i) ao cálculo do indicador de gastos com pessoal, o qual atribui valor zero a municípios que desembolsam com folha de pagamento mais de $60 \%$ da $\mathrm{RCL}$, e valor máximo àqueles que despendem menos de $30 \%$ com pessoal (SISTEMA FIRJAN, 2017c), valorizando sobremaneira a gestão menos intensiva em capital humano; e ii) aos serviços públicos prestados pelos municípios - e.g., educação infantil e fundamental, assistência social e atenção básica em saúde - bastante dependentes de capital humano. Assim, é possível que as localidades mais bem-sucedidas em atender a demandas por serviços tenham orçamento mais pressionado pelos gastos com pessoal. 
Alinhamento partidário com o governador associa-se com maior liquidez. Esse componente do IFGF parece favorecer-se pelas transferências voluntárias, porém estas mostram uma relação mais intensa com investimentos, como esperado. A cota do FPM associa-se negativamente com os componentes do IFGF, exceto pelo custo da dívida. Essas estimativas estão alinhadas à expectativa com relação aos indicadores de arrecadação própria e investimentos; a associação negativa do FPM com rigidez orçamentária e liquidez é sugestiva de flypaper effect. Prefeitos em segundo mandato consecutivo tendem a experimentar menores percentuais de gastos com pessoal, ceteris paribus. Dominância eleitoral relaciona-se negativamente com receitas próprias, todavia o coeficiente estimado é de expressão tímida $(-0,015)$. Em conjunto, a análise dos componentes do IFGF sugere sensibilidade aos fatores elencados no modelo teórico, reforçando a presunção de validade deste.

A especificação principal (8, Tabela 2) é capaz de prever $70 \%$ da variação do IFGF . O restante é, por exclusão, atribuível à qualidade da gestão fiscal municipal. Tendose calculado os resíduos via especificação (8), o foco analítico desloca-se agora para o exame de sua distribuição. A Tabela 3 traz correlações entre as variáveis não categóricas do modelo de regressão e os resíduos; estes correlacionam-se positivamente com tais covariáveis, à exceção do PIB per capita ${ }_{(\mathrm{t}-1)}$ e das transferências discricionárias. População apresenta a associação de maior magnitude com os resíduos, acima de 0,3; em segundo e terceiro lugares, liquidez e FPM mostram correlações na faixa de 0,2. TVU associamse negativamente aos resíduos, porém essa correlação é de magnitude imaterial (|corr| $<0,03)$, enquanto a correlação com as transferências voluntárias do estado não é estatisticamente diferente de zero. 
Tabela 03 | Correlações com resíduos

\begin{tabular}{|c|c|c|}
\hline Variável & Correlação & p-valor \\
\hline IFGF Receita própria ${ }_{(t-1)}$ & 0,0474 & 0,0000 \\
\hline IFGF Rigidez orçamentária $_{(\mathrm{t}-1)}$ & 0,1481 & 0,0000 \\
\hline IFGF Liquidez $_{(\mathrm{t}-1)}$ & 0,2422 & 0,0000 \\
\hline IFGF Investimentos $_{(t-1)}$ & 0,1575 & 0,0000 \\
\hline IFGF Custo da dívida ${ }_{(\mathrm{t}-1)}$ & 0,1131 & 0,0000 \\
\hline PIB p.c.(R\$ milhares) ${ }_{(\mathrm{t}-1)}$ & $-0,0599$ & 0,0000 \\
\hline População (milhares de pessoas) ${ }_{(\mathrm{t}-1)}$ & 0,3087 & 0,0000 \\
\hline IFDM $_{(t-1)}$ & 0,0807 & 0,0000 \\
\hline Cota do FPM (\% das receitas) ${ }_{t}$ & 0,1643 & 0,0000 \\
\hline Transferências voluntárias da União (\% das receitas) & $-0,0298$ & 0,0092 \\
\hline Transferências voluntárias do estado (\% das receitas) ${ }_{t}$ & $-0,0104$ & 0,3643 \\
\hline Votos válidos recebidos pelo prefeito $(\%)_{t}$ & 0,0276 & 0,0160 \\
\hline \multicolumn{3}{|l|}{ Votos válidos recebidos pelo prefeito $(\%)_{\mathrm{t}}$ * } \\
\hline Prefeito em segundo mandato consecutivo ${ }_{t}$ & 0,0427 & 0,0002 \\
\hline
\end{tabular}

Notas: Os p-valores referem-se a testes t de significância estatística da correlação. Observações = 7.633.

Fonte: Elaboração própria.

Testes $t$ de diferença de médias (não mostrados ${ }^{13}$ ) entre grupos definidos a partir de variáveis binárias selecionadas (dummies de alinhamento partidário ${ }^{14}$, prefeito em segundo mandato consecutivo, ano de eleição geral, e ano de eleição municipal), indicam que esses grupos não apresentam médias díspares - ressalva feita às observações referentes a localidades com prefeito reeleito, as quais apresentam resíduo em média 0,8 ponto maior.

Como forma de sintetizar a distribuição espacial dos resíduos, obteve-se o resíduo médio de cada município. A Figura 2 mapeia essas médias, que apresentam valor mínimo, mediano e máximo de $-18,15,-0,19$ e 87,11 , respectivamente. Dos 853 municípios mineiros, apenas um (Ponto Chique, na região de Montes Claros) não dispunha de informação completa em qualquer dos anos entre 2007 e 2016 e não se representou nas regressões. 
Figura 02 | Mapa dos municípios mineiros segundo o resíduo médio (2007-2016)

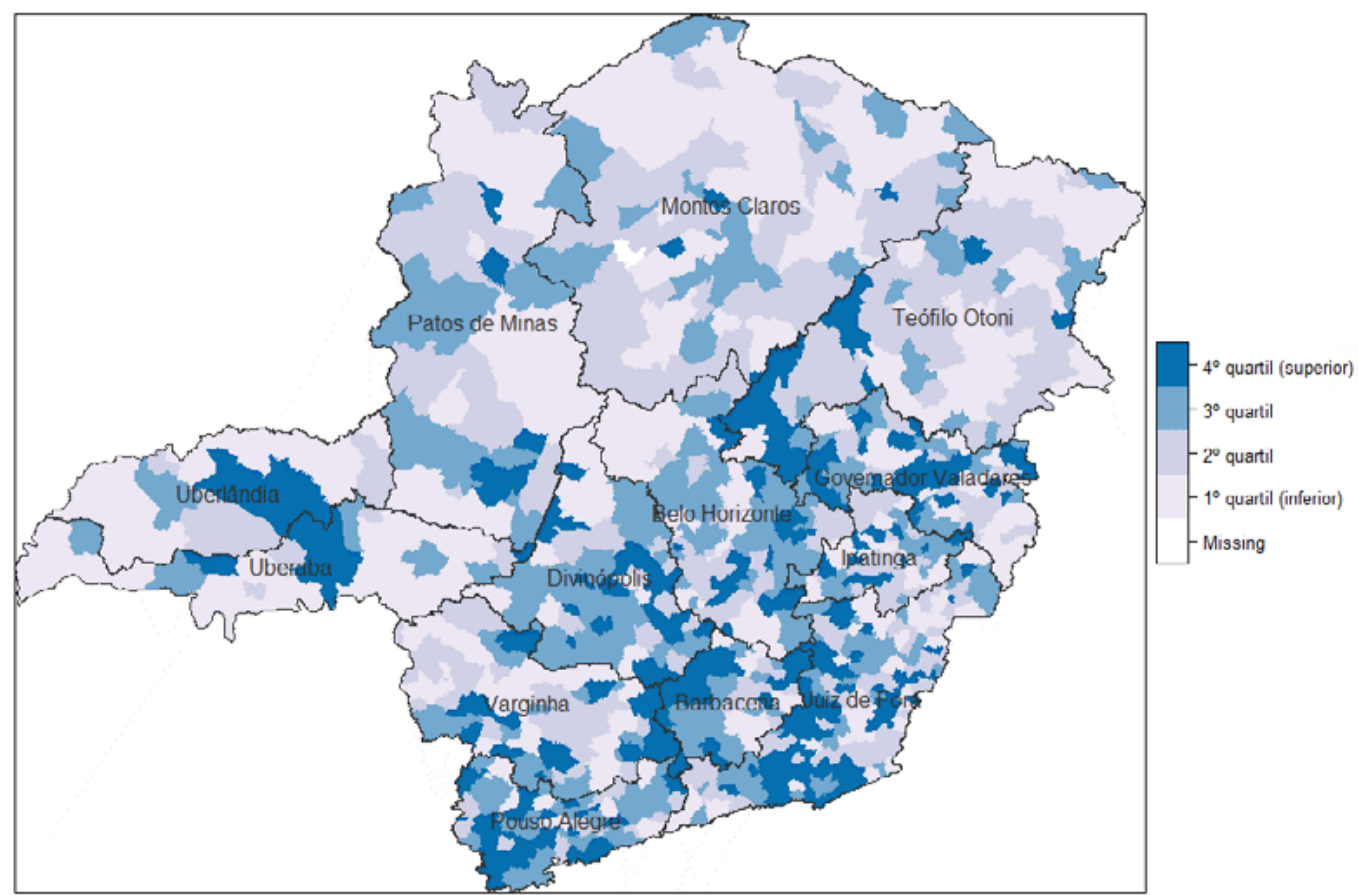

Fonte: elaboração própria.

A Figura 2 descola-se da frequente divisão espacial dos indicadores socioeconômicos de Minas Gerais, os quais revelam marcante concentração de desenvolvimento no Oeste, Sul e centro do estado, como ilustra a Figura 3. Ainda assim, há sinais de dependência espacial dos resíduos, a qual é explorada nas análises adiante ${ }^{15}$. 0 índice $I$ de Moran assume valor 0,186 , e é estatisticamente significante a $1 \%{ }^{16}$. Esse indicador, que varia de -1 a 1, reporta a intensidade da autocorrelação espacial - um padrão de dependência em que a magnitude de uma variável de interesse (e.g., número de crimes violentos) em uma localidade (e.g., um setor censitário) é determinada pelos, ou pelo menos associada com, valores dessa mesma variável em outras localidades no sistema (ANSELIN, 2003, p. 310).

Figura 03 | Mapa dos municípios mineiros segundo variáveis selecionadas (2010) 
a) Regiões intermediárias

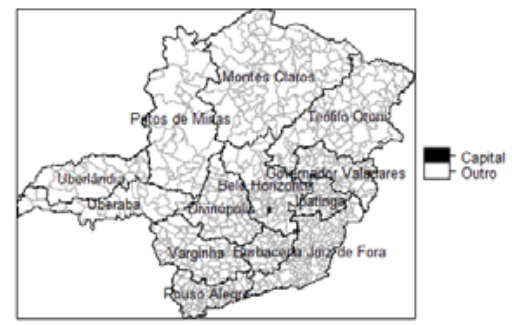

c) \% até 14 anos em domicilios sem EF; I = 0,446

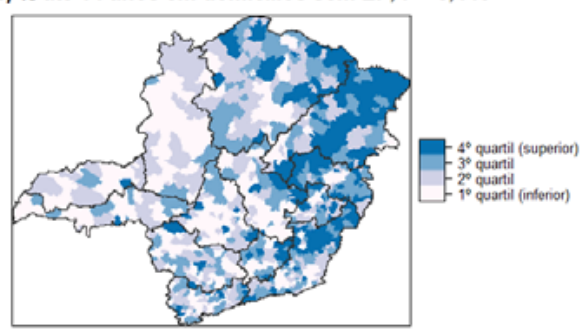

b) Renda per capita média; I = 0,561

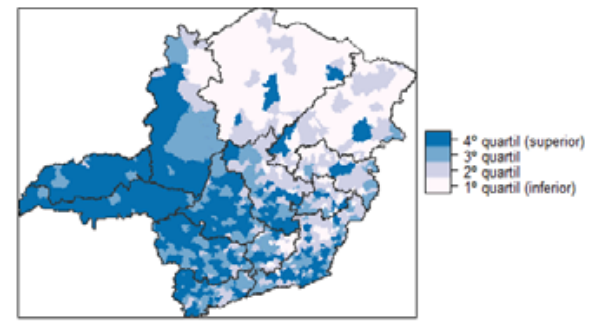

d) Esperança de vida ao nascer; $\mathrm{I}=0,456$

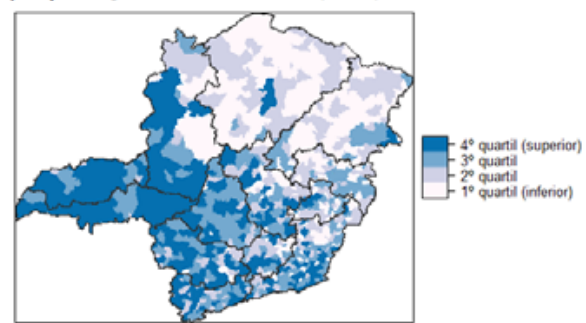

Notas: I = I de Moran; esse indicador é estatisticamente significante a $1 \%$ para as variáveis descritas nos painéis b), c) e d). Figura 3c) apresenta o percentual de crianças até 14 anos morando em domicílios onde ninguém tem ensino fundamental. Fonte: elaboração própria, com base em dados brutos do "Atlas do Desenvolvimento Humano no Brasil" (www.atlas.brasil. org.br).

A seu turno, Local Indicators of Spatial Autocorrelation (LISA), como o I de Moran local exibido na Figura 4, são capazes de detectar diferentes regimes de associação espacial, pois consideram não a área como um todo (aqui, Minas Gerais), mas cada município e seus vizinhos. LISA são úteis para uma análise espacial exploratória, pontuando eventuais clusters e formando a base para a análise de outliers (ANSELIN, 1995). Agrupamentos LISA alto-alto (baixo-baixo) reúnem municípios próximos com resíduos acima (abaixo) da média. 
Figura 04 | Mapa de autocorrelação espacial local (LISA) do resíduo médio (2007-2016)

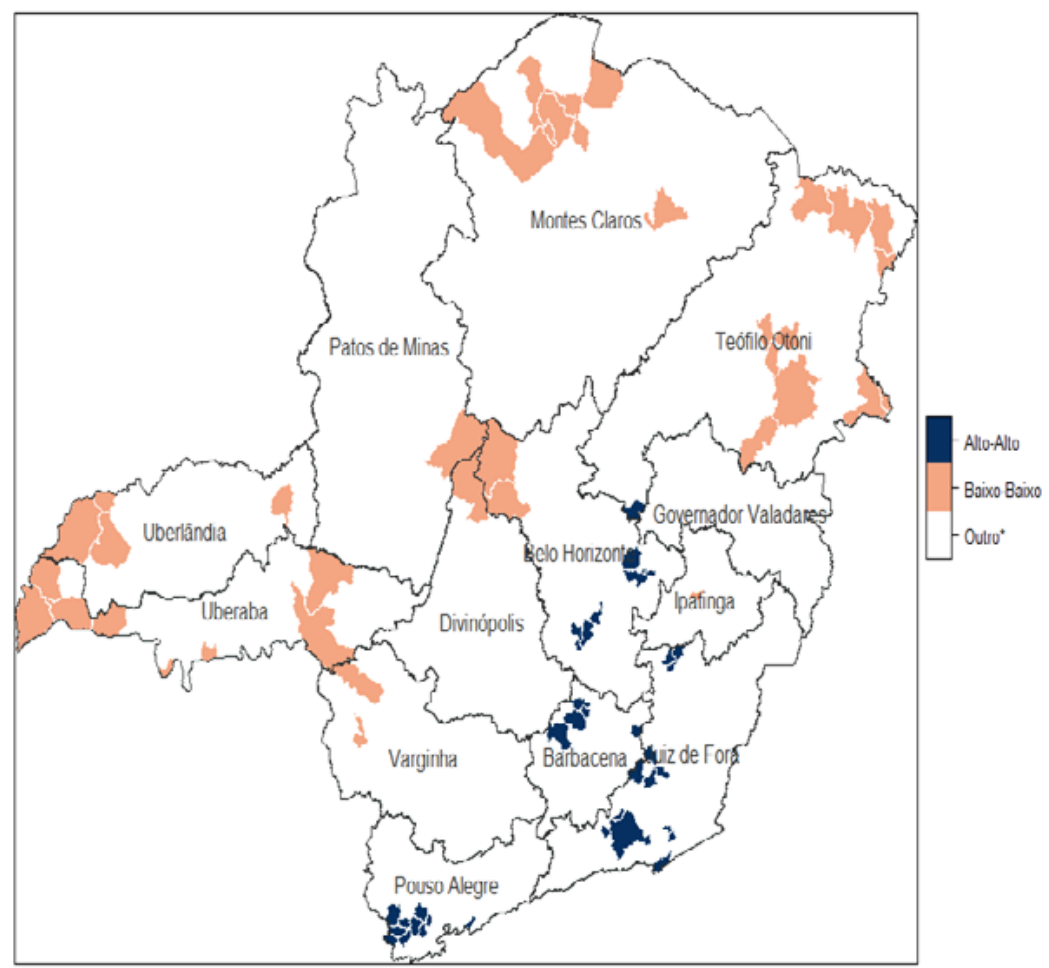

Nota: * LISA misto (alto-baixo, baixo-alto) ou não estatisticamente significante a $5 \%$.

Fonte: elaboração própria.

O mapa dos LISA da média dos resíduos (Figura 4) não identifica clusters cobrindo porções relativamente extensas do território. Os agrupamentos destacados nessa figura coincidem com os clusters mais recorrentemente identificados nas análises ano a ano, detalhadas na Figura A1, do Apêndice. Via de regra, agrupamentos alto-alto ocorrem nas regiões central e meridional do estado. O Oeste normalmente apresenta indicadores socioeconômicos acima da média (Figura 3), todavia exibiu cluster altoalto apenas em 2013.

Clusters alto-alto e baixo-baixo mostram-se descontínuos e, no mais das vezes, efêmeros. Dentre os 853 municípios do estado, 96 figuraram como alto-alto pelo menos uma vez (Tabela 4). No total, 192 observações (combinações município-ano) apresentaram esse status (uma média de 2,0 observações por município). Registraram- 
se 280 observações com LISA baixo-baixo, espalhadas por 158 municípios (média = 1,8 observação por município). Os agrupamentos baixo-baixo mostraram-se cerca de $45 \%$ mais frequentes que os alto-alto, mas com grau similar de dispersão: dos municípios com LISA estatisticamente significante, mais de $85 \%$ têm até três LISA alto-alto ou baixo-baixo. Além disso, apenas quatro municípios apresentam-se como baixo-baixo e cinco como alto-alto mais que cinco vezes - destes cinco, quatro pertencem à região intermediária de Belo Horizonte, e um à de Pouso Alegre, no sul do estado (Tabela A2, do Apêndice).

Tabela 04 | LISA estatisticamente significante a 5\%, por número de observações e municípios: clusters alto-alto e baixo-baixo

\begin{tabular}{|c|c|c|c|c|c|c|c|c|}
\hline Vezes & $\begin{array}{c}\text { Observações } \\
\text { Alto-Alto }\end{array}$ & $\begin{array}{l}\text { Municípios } \\
\text { Alto-Alto }\end{array}$ & $\begin{array}{l}\text { Percentual de } \\
\text { observações } \\
\text { Alto-Alto }\end{array}$ & $\begin{array}{l}\text { Percentual } \\
\text { de } \\
\text { municípios } \\
\text { Alto-Alto }\end{array}$ & $\begin{array}{c}\text { Observações } \\
\text { Baixo-Baixo }\end{array}$ & $\begin{array}{l}\text { Municípios } \\
\text { Baixo-Baixo }\end{array}$ & $\begin{array}{l}\text { Percentual de } \\
\text { observações } \\
\text { Baixo-Baixo }\end{array}$ & $\begin{array}{c}\text { Percentual } \\
\text { de } \\
\text { municípios } \\
\text { Baixo-Baixo }\end{array}$ \\
\hline 1 & 58 & 58 & 30,21 & 60,42 & 89 & 89 & 31,79 & 56,33 \\
\hline 2 & 34 & 17 & 17,71 & 17,71 & 80 & 40 & 28,57 & 25,32 \\
\hline 3 & 24 & 8 & 12,50 & 8,33 & 48 & 16 & 17,14 & 10,13 \\
\hline 4 & 28 & 7 & 14,58 & 7,29 & 36 & 9 & 12,86 & 5,70 \\
\hline 5 & 5 & 1 & 2,60 & 1,04 & 0 & 0 & 0,00 & 0,00 \\
\hline 6 & 6 & 1 & 3,13 & 1,04 & 12 & 2 & 4,29 & 1,27 \\
\hline 7 & 0 & 0 & 0,00 & 0,00 & 7 & 1 & 2,50 & 0,63 \\
\hline 8 & 8 & 1 & 4,17 & 1,04 & 8 & 1 & 2,86 & 0,63 \\
\hline 9 & 9 & 1 & 4,69 & 1,04 & 0 & 0 & 0,00 & 0,00 \\
\hline 10 & 20 & 2 & 10,42 & 2,08 & 0 & 0 & 0,00 & 0,00 \\
\hline Total & 192 & 96 & 100,00 & 100,00 & 280 & 158 & 100,00 & 100,00 \\
\hline
\end{tabular}

Fonte: elaboração própria.

Em conjunto, as análises geográficas indicam que: i) a proxy para qualidade da gestão fiscal tende a apresentar um padrão de distribuição espacial menos concentrado que aquele dos indicadores socioeconômicos e que, possivelmente, responde ou associase a algumas influências diferentes das socioeconômicas; ii) apenas uma mínima fração dos focos de maior ou menor qualidade da gestão fiscal é persistente; e iii) agrupamentos recorrentes de maior qualidade da gestão fiscal concentram-se na região da capital. 


\section{Considerações finais}

Este trabalho buscou enumerar e articular a gama de condicionantes do desempenho fiscal local, dimensionar a influência da gestão fiscal municipal nesse desempenho, e descrever como a qualidade da gestão fiscal se distribui entre municípios com diferentes características. Enfrentou o desafio teórico de conceituar as noções de qualidade da gestão fiscal e de desempenho fiscal, e organizou os fatores atuantes sobre este num modelo integrado, tributário de diferentes campos de estudo atinentes a temas como gestão financeira em nível subnacional, federalismo fiscal e (des)centralização, distributive politics e ciclos políticos.

O exercício empírico estimou um modelo de regressão com efeitos fixos de município (cross section) e de ano, tendo como variável dependente o desempenho fiscal (IFGF) dos municípios mineiros, no intervalo 2007-2016. Singularidades locais constantes no tempo explicam mais da metade da variação do IFGF. Desempenho fiscal no ano anterior, representado pelos componentes do IFGF, associa-se positivamente ao índice, porém em intensidade modesta. PIB municipal per capita e tamanho populacional não apresentam associação detectável com o IFGF em quase todas as especificações experimentadas.

Estimativas indicam que o efeito das transferências intergovernamentais é condicional ao tipo de transferência. Enquanto o FPM exibe relação inversa com o IFGF, as transferências discricionárias da União e do estado parecem favorecer o desempenho fiscal do município, especialmente pela via dos investimentos. Esses resultados são consistentes com a hipótese de flypaper effect, visto que o FPM é um recurso de baixo custo político e administrativo para a gestão municipal, e não condicionado a um uso específico - diferentemente dos repasses voluntários, que financiam projetos previamente elaborados e podem requerer uma contrapartida orçamentária do governo local, além de eventual esforço de prospecção de convênios.

Dois conjuntos de evidências reforçam a presunção de validade do modelo teórico proposto. De um lado, as associações do IFGF com variáveis políticas (e.g., alinhamento partidário com governador) mostram-se mais salientes em anos de eleições municipais. De outro, regressões dos indicadores componentes do IFGF sugerem sensibilidade aos fatores elencados no modelo conceitual. 
O modelo empírico completo é capaz de prever mais de dois terços da variação do IFGF; o restante é, por eliminação, considerado resultante de heterogeneidades na gestão fiscal. Os resíduos, proxy para qualidade da gestão fiscal, apresentam moderada correlação (da ordem de 0,3 ) com a população do município. Essa proxy se mostra mais elevada em municípios onde o prefeito foi reeleito no último pleito.

As análises geográficas dos resíduos informam que estes exibem um padrão de distribuição espacial menos concentrado que aquele de alguns dos indicadores socioeconômicos tradicionais e que, possivelmente, a qualidade da gestão fiscal é produzida por processos diferentes dos subjacentes a esses indicadores. Agrupamentos alto-alto ocorrem no centro e Sul do estado. Apenas uma pequena fração dos focos de maior ou menor qualidade da gestão fiscal é recorrente, e os clusters persistentes de maior qualidade da gestão fiscal tendem a se localizar na região de Belo Horizonte.

Acredita-se que o modelo conceitual para o desempenho fiscal, ao contemplar influências estruturais e conjunturais, represente uma inovação relevante para a compreensão das finanças municipais. Ao mesmo tempo, cabe reconhecer duas limitações do estudo. Primeiro, os modelos de desempenho fiscal estimados não incorporam fatores que se alteram simultaneamente no tempo e no espaço (além daqueles diretamente introduzidos como covariáveis); instância desse tipo de fator seria eventual sensibilidade diferencial entre municípios às dificuldades fiscais enfrentadas pelo governo estadual (as quais redundam em, por exemplo, atraso nos repasses constitucionais). Segundo, ao apoiar-se num indicador composto, o IFGF, o trabalho passa a carregar as limitações deste, tais como a arbitrariedade na estipulação de pesos e limiares, a exemplo do limite relacionado à rigidez orçamentária: o indicador dessa dimensão assume valor máximo quando as despesas com folha de pagamento são inferiores a $30 \%$ da RCL - um percentual baixo considerando-se as responsabilidades municipais na prestação de serviços intensivos em trabalho.

Como agenda de pesquisa futura, propõe-se explorar outros indicadores de desempenho fiscal, testando-se dessa forma a sensibilidade dos resultados aqui obtidos. Também, interessa investigar explicações para a aparente superioridade da gestão fiscal nos municípios de maior porte e aqueles próximos a Belo Horizonte. Nesse sentido, uma linha de estudo seria pesquisar a possível existência de um link causal conectando 
a escolaridade da burocracia e de representantes eleitos a diferentes facetas da gestão fiscal dos municípios.

Mais que isso, considerando um escopo territorial expandido e a necessidade de se controlar por outras manifestações da capacidade de gestão financeira (além da qualificação de gestores e legisladores), faz-se imprescindível aprofundar esforços como o de Veloso et al. (2011). O entendimento de como, e em que medida, capacidade de gestão associa-se com desempenho fiscal requer levantamento de dados sobre diversos aspectos daquela - e.g., investimentos dos governos municipais na burocracia pública, em sistemas de arrecadação, no controle e transparência do gasto público. A coleta desses dados poderia realizar-se por meio de surveys, como fizeram Veloso et al. (2011), ou via processos institucionalizados e incentivados, a exemplo do Índice de Gestão Descentralizada do Programa Bolsa Família e do Cadastro Único (IGD), desenvolvido em 2006 pelo então Ministério de Desenvolvimento Social e Combate à Fome. Essa iniciativa implementou um mecanismo de apoio financeiro baseado em indicadores de gestão, que se presta primordialmente a fomentar a atualização dos cadastros das famílias e o acompanhamento das condicionalidades (MDS, 2018). Nesse processo, são regularmente apuradas e disponibilizadas informações sobre a gestão local da assistência social. Na área fiscal, iniciativa semelhante possibilitaria a produção de dados que, além de imediatamente relevantes para a administração pública, permitiriam avançar a compreensão das condições indutoras do desempenho fiscal dos municípios. 


\section{Referências bibliográficas}

AlesinA, A. Macroeconomic policy in a two-party system as a repeated game. Quarterly Journal of Economics, v. 102, n. 3, p. 651-678, 1987.

ANSELIN, L. Local Indicators of Spatial Association - LISA. Geographical Analysis, v. 27, n. 2, p. 93115, 1995.

ANSELIN, L. Spatial econometrics. In: BALTAGI, B. H. (org.). A companion to theoretical econometrics. Malden: Blackwell Publishing, 2003, p. 310-330.

ARAúJo JúNIOR, J. G. de. Uma análise fiscal dos novos municípios mineiros: dependência e distorções federativas. 138f. Dissertação (Mestrado em Ciência Política) - Faculdade de Filosofia e Ciências Humanas, Universidade Federal de Minas Gerais (UFMG), Belo Horizonte. 2016.

ARRETCHE, M. Federalismo e políticas sociais no Brasil: problemas de coordenação e autonomia. São Paulo em Perspectiva, v. 18, n. 2, p. 17-26, 2004.

ARRETCHe, M. Democracia, federalismo e centralização no Brasil. Rio de Janeiro: Fundação Getulio Vargas/ Fiocruz, 2012.

BAIÃo, A.; CUNHA, A.; SouZA, F. Papel das transferências intergovernamentais na equalização fiscal dos municípios brasileiros. Revista do Serviço Público, v. 68, n. 3, 2017.

BATISTA, M. Burocracia local e qualidade da implementação de políticas descentralizadas: uma análise da gestão de recursos federais pelos municípios brasileiros. Revista do Serviço Público, v. 66, n. 3, p. 345-370, 2015.

Bertholini, F.; Pereira, C.; Rennó, L. Pork is policy: dissipative inclusion at the local level. Governance, v. 31, n. 4, p. 701-720, 2018.

BRolLO, F.; NANNICINI, T. Tying your enemy's hands in close races: the politics of federal transfers in Brazil. American Political Science Review, v. 106, n. 4, p. 742-761, 2012.

BUENO, N. Bypassing the enemy: distributive politics, credit claiming, and nonstate organizations in Brazil. Comparative Political Studies, v. 51, n. 3, p. 304-340, 2018.

CINGOLANI, L. The state of state capacity: a review of concepts, evidence and measures. Working Paper Series on Institutions and Economic Growth, Netherlands, 2013. Disponível em: <https:// cris.maastrichtuniversity.nl/portal/en/publications/the-state-of-state-capacity--a-review-ofconcepts-evidence-and-measures(08eddd61-296c-4612-9254-277934f3be51).html>. Acesso em: 18 fevereiro 2019.

Cingolani, L.; ThOmsson, K.; Crombrugghe, D. de. Minding Weber more than ever? The impacts of state capacity and bureaucratic autonomy on development goals. World Development, v. 72, p. 191-207, 2015.

COSTA, R. F. R.; CASTELAR, L. I. M. O impacto das transferências constitucionais sobre os gastos dos municípios brasileiros. Análise Econômica, v. 33, n. 64, p.171-189, 2015. 
GobetTI, S. W.; KLERING, L. R. Índice de Responsabilidade Fiscal e Qualidade de Gestão: uma análise combinada baseada em indicadores de estados e municípios, 2007. Monografia premiada em $1^{\circ}$ lugar no Tema "Lei de Responsabilidade Fiscal" do XII Prêmio Tesouro Nacional - 2007. Disponível em: <http://www.tesouro.fazenda.gov.br/documents/10180/236137/P5_1_2007.pdf/ e39953af-49d6-43e5-86b0-ab512933bc21>. Acesso em: 27 de fev. 2019.

Gomide, A. de A.; BoschI, R. R. (orgs.). Capacidades estatais em países emergentes: o Brasil em perspectiva comparada. Brasília: Ipea, 2016.

HibBS JR., D. A. Political parties and macroeconomic policy. American Political Science Review, v. 71, n. 4, p. 1467-1487, 1977.

Hou, Y. Putting money where the need is: managing the finances of state and local governments. In: INGRAHAM, P. W. (org.). In pursuit of performance: management systems in state and local government. Baltimore: The Johns Hopkins University Press, 2007, p. 15-56.

INGRAHAM, P. W. Studying state and local government management systems: why we need to do it. In: INGRAHAM, P. W. (org.). In pursuit of performance: management systems in state and local government. Baltimore: The Johns Hopkins University Press, 2007, p. 1-14.

INGRAHAM, P. W.; JOYCE, P. G.; DonAHUE, A. K. Government performance: why management matters. Baltimore, The Johns Hopkins University Press, 2003.

Marenco, A.; Strohschoen, M.; Joner, W. Capacidade estatal, burocracia e tributação nos municípios brasileiros. Revista de Sociologia e Política, v. 25, n. 64, p. 3-21, 2017.

Mattos, E.; Rocha, F; ARVATE, P. Flypaper effect revisited: evidence for tax collection efficiency in Brazilian municipalities. Estudos Econômicos, v. 41, n. 2, p. 239-267, 2011.

MINISTÉRIO do DeSEnVOLVIMENTO SOCIAL (MDS). Caderno do IGD-M: manual do Índice de Gestão Descentralizada do Programa Bolsa Família e do Cadastro Único (municípios e Distrito Federal). Brasília: Ministério do Desenvolvimento Social, 2018.

MEIRELES, F. Alinhamento partidário e demanda por transferências federais no Brasil. Revista de Administração Pública-RAP, v. 53, n. 1, p. 173-194, 2019.

Nordhaus, W. D. The political business cycle. The Review of Economic Studies, v. 42, n. 2, p. 169190, 1975.

NUNes, F. Presidentialism, decentralization, and distributive politics in Latin America. $2015155 f$. Tese (Doutorado em Ciência Política) - University of California, Los Angeles (UCLA), Los Angeles.

OLIVEIRA, F. Teorias da federação e do federalismo fiscal: o caso brasileiro. Texto para Discussão n. 43. Belo Horizonte: Fundação João Pinheiro, 2007.

PRADO, S. Transferências fiscais e financiamento municipal no Brasil. São Paulo: Ebap, 2001.

Puttomattı, G. Capital político e transferências voluntárias no Estado de São Paulo. $201373 f$. Dissertação (Mestrado em Administração Pública e Governo) - Escola de Administração de Empresas de São Paulo (Eaesp), Fundação Getulio Vargas (FGV), São Paulo. 
Rezende, F.; Afonso, J. R. A reforma fiscal no processo de elaboração da nova constituição. Texto para Discussão Interna n. 121. Rio de Janeiro: Ipea, 1987.

ROGOFF, K.; SiberT, A. Elections and macroeconomic policy cycles. The Review of Economic Studies, v. 55, n. 1, p. 1-16, 1988.

SAKURAI, S. Ciclos políticos nas funções orçamentárias dos municípios brasileiros: uma análise para o período 1990-2005 via dados em painel. Estudos Econômicos, v. 39, n, 1, p. 39-58, 2009.

SAKURAI, S. Efeitos assimétricos das transferências governamentais sobre os gastos públicos locais: evidências em painel para os municípios brasileiros. Pesquisa e Planejamento Econômico, v. 43, n. 2, p. 309-332, 2013.

Sakural, S.; Gremaud, A. P. Political business cycles: evidências empíricas para os municípios paulistas (1989-2001). Revista de Economia Aplicada, v. 11, n. 1, p. 27-54, 2007.

SISTEMA FIRJAN. IFDM 2015: Índice Firjan de Desenvolvimento Municipal (Ano-base 2013). Rio de Janeiro: Sistema Firjan, 2015. Disponível em: <http://www.firjan.com.br/ifdm/downloads/>. Acesso em: 02 de jan. 2018.

SISTEMA FIRJAN. IFGF 2017: Índice Firjan de Gestão Fiscal (Ano-base 2016). Rio de Janeiro: Sistema Firjan, 2017a. Disponível em: <http://www.firjan.com.br/ifgf/downloads/>. Acesso em: 31 de maio 2018.

SISTEMA FIRJAN. IFGF 2017: Índice Firjan de Gestão Fiscal (Ano-base 2016) - Análise especial Minas Gerais. Rio de Janeiro: Sistema Firjan, 2017b. Disponível em: <http://www.firjan.com.br/ifgf/ downloads/>. Acesso em: 31 de maio 2018.

SISTEMA FIRJAN. IFGF 2017: Índice Firjan de Gestão Fiscal (Ano-base 2016) - Anexo metodológico. Rio de Janeiro: Sistema Firjan, 2017c. Disponível em: <http://www.firjan.com.br/ifgf/downloads>. Acesso em: 31 de maio 2018.

SOARES, J. F.; ALVES, M. T. G. Efeitos de escolas e municípios na qualidade do ensino fundamental. Cadernos de Pesquisa, v. 43, n. 149, p. 492-517, 2013.

SOARES, M.; Melo, B. Condicionantes políticos e técnicos das transferências voluntárias da União aos municípios brasileiros. Revista de Administração Pública-RAP, v. 50, n. 4, p. 539-562, 2016.

SECRETARIA DO TESOURO NACIONAL (STN). O que você precisa saber sobre as transferências fiscais da União: Fundo de Participação dos Municípios - FPM. Brasília: Secretaria do Tesouro Nacional, 2018.

Stokes, S.; Dunning, T.; NAZAREno, M.; Brusco, V. Brokers, voters, and clientelism: the puzzle of distributive politics. New York: Cambridge University Press, 2013.

SURI, T.; BOOZER, M. A.; RANIS, G.; STEWART, F. Paths to success: the relationship between human development and economic growth. World Development, v. 39, n. 4, p. 506-522, 2011.

TWISK, J.; RIJMEN, F. Longitudinal tobit regression: a new approach to analyze outcome variables with floor or ceiling effects. Journal of Clinical Epidemiology, v. 62, n. 9, p. 953-958, 2009. 
Veloso, J.; Monasterio, L.; Vieira, R.; MiRAndA, R. Uma visão inicial dos subsistemas da gestão pública municipal. In: Veloso, J.; MonASTERIO, L.; VIEIRA, R.; MIRANDA, R. (orgs.). Gestão municipal no Brasil: um retrato das prefeituras. Brasília: Ipea, 2011, p. 11-39.

\section{Ana Paula Karruz}

(iD) https://orcid.org/0000-0002-8200-0121

Universidade Federal de Minas Gerais (UFMG)

Doutora em Políticas Públicas e Administração Pública pela George Washington University, Estados Unidos. Mestre em Administração Pública e Governo pela Escola de Administração de Empresas de São Paulo da Fundação Getulio Vargas. Bacharel em Ciências Econômicas pela Universidade de São Paulo.

$凶$ apkarruz@gmail.com

\section{André Machado Moraes}

(iD) https://orcid.org/0000-0002-6004-8968

Banco de Desenvolvimento de Minas Gerais (BDMG)

Bacharel em Gestão Pública pela Universidade Federal de Minas Gerais.

$\bowtie$ andremacmoraes@gmail.com 


\section{Apêndice}

Tabela A1 | Coeficientes de regressão estimados, tendo os componentes do IFGF $_{t}$ como variável dependente (modelos tobit)

\begin{tabular}{|c|c|c|c|c|c|}
\hline \multirow[b]{2}{*}{$\begin{array}{l}\text { Variável } \\
\text { independente }\end{array}$} & \multicolumn{5}{|c|}{ Variável dependente } \\
\hline & $\begin{array}{l}\text { IFGF Receita } \\
\text { própria }_{t}\end{array}$ & $\begin{array}{l}\text { IFGF Rigidez } \\
\text { orçamentária }_{t}\end{array}$ & $\begin{array}{l}\text { IFGF } \\
\text { Liquidez }\end{array}$ & $\begin{array}{l}\text { IFGF } \\
\text { Investimentos }\end{array}$ & $\begin{array}{l}\text { IFGF Custo } \\
\text { da dívida }{ }_{t}\end{array}$ \\
\hline $\begin{array}{l}\text { IFGF Receita } \\
\text { própria }_{(\mathrm{t}-1)}\end{array}$ & $\begin{array}{l}0,604 * * * \\
(0,059)\end{array}$ & $\begin{array}{l}-0,087^{* * *} \\
(0,018)\end{array}$ & $\begin{array}{l}0,051 \\
(0,060)\end{array}$ & $\begin{array}{l}-0,064^{*} \\
(0,037)\end{array}$ & $\begin{array}{l}-0,017 \\
(0,013)\end{array}$ \\
\hline $\begin{array}{l}\text { IFGF Rigidez } \\
\text { orçamentária }_{(\mathrm{t}-1)}\end{array}$ & $\begin{array}{l}-0,005 \\
(0,007)\end{array}$ & $\begin{array}{l}0,375^{* * *} \\
(0,027)\end{array}$ & $\begin{array}{l}-0,011 \\
(0,037)\end{array}$ & $\begin{array}{l}0,115^{* * *} \\
(0,019)\end{array}$ & $\begin{array}{l}0,003 \\
(0,009)\end{array}$ \\
\hline IFGF Liquidez $_{(t-1)}$ & $\begin{array}{l}0,006 * * \\
(0,002)\end{array}$ & $\begin{array}{l}-0,009 \\
(0,007)\end{array}$ & $\begin{array}{l}0,792 * * * \\
(0,038)\end{array}$ & $\begin{array}{l}0,159 * * * \\
(0,010)\end{array}$ & $\begin{array}{l}0,026 * * * \\
(0,003)\end{array}$ \\
\hline $\begin{array}{l}\text { IFGF } \\
\text { Investimentos }_{(\mathrm{t}-1)}\end{array}$ & $\begin{array}{l}-0,007^{* * *} \\
(0,003)\end{array}$ & $\begin{array}{l}0,014^{* *} \\
(0,006)\end{array}$ & $\begin{array}{l}-0,017 \\
(0,020)\end{array}$ & $\begin{array}{l}0,170 * * * \\
(0,016)\end{array}$ & $\begin{array}{l}-0,015^{* * *} \\
(0,004)\end{array}$ \\
\hline $\begin{array}{l}\text { IFGF Custo da } \\
\text { dívida }_{(\mathrm{t}-1)}\end{array}$ & $\begin{array}{l}-0,002 \\
(0,006)\end{array}$ & $\begin{array}{l}0,028 * * \\
(0,014)\end{array}$ & $\begin{array}{l}0,128 * * * \\
(0,038)\end{array}$ & $\begin{array}{l}0,076 * * * \\
(0,018)\end{array}$ & $\begin{array}{l}0,738 * * * \\
(0,012)\end{array}$ \\
\hline $\begin{array}{l}\text { PIB p.c. (R\$ } \\
\text { milhares) } \\
(\mathrm{t}-1)\end{array}$ & $\begin{array}{l}-0,004 \\
(0,009)\end{array}$ & $\begin{array}{l}0,039 * * \\
(0,016)\end{array}$ & $\begin{array}{l}-0,021 \\
(0,034)\end{array}$ & $\begin{array}{l}0,025 \\
(0,034)\end{array}$ & $\begin{array}{l}0,026 * * * \\
(0,008)\end{array}$ \\
\hline $\begin{array}{l}\text { População (milhares } \\
\text { de pessoas) } \\
(\mathrm{t}-1)\end{array}$ & $\begin{array}{l}0,011 \\
(0,008)\end{array}$ & $\begin{array}{l}0,007 \\
(0,005)\end{array}$ & $\begin{array}{l}-0,022^{*} \\
(0,012)\end{array}$ & $\begin{array}{l}0,002 \\
(0,020)\end{array}$ & $\begin{array}{l}-0,002 \\
(0,001)\end{array}$ \\
\hline $\operatorname{IFDM}_{(\mathrm{t}-1)}$ & $\begin{array}{l}0,095^{* * *} \\
(0,014)\end{array}$ & $\begin{array}{l}-0,117^{* * *} \\
(0,027)\end{array}$ & $\begin{array}{l}0,331^{* * *} \\
(0,096)\end{array}$ & $\begin{array}{l}0,178 * * * \\
(0,056)\end{array}$ & $\begin{array}{l}0,016 \\
(0,018)\end{array}$ \\
\hline $\begin{array}{l}\text { Prefeito do } \\
\text { mesmo partido do } \\
\text { presidente }_{t}\end{array}$ & $\begin{array}{l}-0,177 \\
(0,239)\end{array}$ & $\begin{array}{l}0,659 * \\
(0,376)\end{array}$ & $\begin{array}{l}2,062 \\
(1,437)\end{array}$ & $\begin{array}{l}-0,461 \\
(0,745)\end{array}$ & $\begin{array}{l}-0,069 \\
(0,355)\end{array}$ \\
\hline $\begin{array}{l}\text { Prefeito do } \\
\text { mesmo partido do } \\
\text { governador }_{t}\end{array}$ & $\begin{array}{l}-0,064 \\
(0,158)\end{array}$ & $\begin{array}{l}0,408 \\
(0,475)\end{array}$ & $\begin{array}{l}2,858 * * \\
(1,364)\end{array}$ & $\begin{array}{l}0,259 \\
(0,753)\end{array}$ & $\begin{array}{l}-0,249 \\
(0,297)\end{array}$ \\
\hline $\begin{array}{l}\text { Cota do FPM (\% das } \\
\text { receitas) }\end{array}$ & $\begin{array}{l}-0,335^{* * *} \\
(0,046)\end{array}$ & $\begin{array}{l}-0,142 * * * \\
(0,027)\end{array}$ & $\begin{array}{l}-0,290 * * * \\
(0,085)\end{array}$ & $\begin{array}{l}-0,226 * * * \\
(0,050)\end{array}$ & $\begin{array}{l}0,094 * * * \\
(0,018)\end{array}$ \\
\hline $\begin{array}{l}\text { Transferências } \\
\text { voluntárias da União } \\
\text { (\% das receitas) }\end{array}$ & $\begin{array}{l}-0,163^{* * *} \\
(0,029)\end{array}$ & $\begin{array}{l}0,076 \\
(0,063)\end{array}$ & $\begin{array}{l}0,928 * * * \\
(0,162)\end{array}$ & $\begin{array}{l}2,972 * * * \\
(0,128)\end{array}$ & $\begin{array}{l}0,015 \\
(0,044)\end{array}$ \\
\hline
\end{tabular}




\begin{tabular}{|c|c|c|c|c|c|}
\hline \multirow[b]{2}{*}{$\begin{array}{l}\text { Variável } \\
\text { independente }\end{array}$} & \multicolumn{5}{|c|}{ Variável dependente } \\
\hline & $\begin{array}{l}\text { IFGF Receita } \\
\text { própria }_{t}\end{array}$ & $\begin{array}{l}\text { IFGF Rigidez } \\
\text { orçamentária }\end{array}$ & $\begin{array}{l}\text { IFGF } \\
\text { Liquidez }\end{array}$ & $\begin{array}{l}\text { IFGF } \\
\text { Investimentos, }\end{array}$ & $\begin{array}{l}\text { IFGF Custo } \\
\text { da dívida } \\
{ }_{t}\end{array}$ \\
\hline $\begin{array}{l}\text { Transferências } \\
\text { voluntárias do } \\
\text { estado (\% das } \\
\text { receitas) }\end{array}$ & $\begin{array}{l}-0,168^{* * *} \\
(0,032)\end{array}$ & $\begin{array}{l}0,103 \\
(0,066)\end{array}$ & $\begin{array}{l}0,689 * * * \\
(0,180)\end{array}$ & $\begin{array}{l}2,822 * * * \\
(0,133)\end{array}$ & $\begin{array}{l}-0,014 \\
(0,046)\end{array}$ \\
\hline $\begin{array}{l}\text { Prefeito em } \\
\text { segundo mandato } \\
\text { consecutivo }_{t}\end{array}$ & $\begin{array}{l}-0,505 \\
(0,618)\end{array}$ & $\begin{array}{l}3,678 * * \\
(1,845)\end{array}$ & $\begin{array}{l}-2,398 \\
(5,510)\end{array}$ & $\begin{array}{l}-2,602 \\
(2,867)\end{array}$ & $\begin{array}{l}0,036 \\
(1,217)\end{array}$ \\
\hline $\begin{array}{l}\text { Votos válidos } \\
\text { recebidos pelo } \\
\text { prefeito }(\%)_{t}\end{array}$ & $\begin{array}{l}-0,015^{* *} \\
(0,007)\end{array}$ & $\begin{array}{l}0,010 \\
(0,019)\end{array}$ & $\begin{array}{l}-0,070 \\
(0,065)\end{array}$ & $\begin{array}{l}0,063^{*} \\
(0,032)\end{array}$ & $\begin{array}{l}-0,005 \\
(0,012)\end{array}$ \\
\hline $\begin{array}{l}\text { Votos válidos } \\
\text { recebidos pelo } \\
\text { prefeito }(\%)_{t}{ }^{*}\end{array}$ & 0,013 & $-0,051$ & 0,020 & 0,073 & $-0,001$ \\
\hline $\begin{array}{l}\text { Prefeito em } \\
\text { segundo mandato } \\
\text { consecutivo }_{t}\end{array}$ & $(0,010)$ & $(0,033)$ & $(0,092)$ & $(0,049)$ & $(0,020)$ \\
\hline$t=2008$ & $\begin{array}{l}-1,268^{* * *} \\
(0,262)\end{array}$ & $\begin{array}{l}3,340 * * * \\
(0,442)\end{array}$ & $\begin{array}{l}5,904^{* * *} \\
(1,567)\end{array}$ & $\begin{array}{l}9,917 * * * \\
(1,041)\end{array}$ & $\begin{array}{l}2,463 * * * \\
(0,479)\end{array}$ \\
\hline$t=2009$ & $\begin{array}{l}-0,280 \\
(0,251)\end{array}$ & $\begin{array}{l}-11,699 * * * \\
(0,608)\end{array}$ & $\begin{array}{l}-4,510 * * * \\
(1,674)\end{array}$ & $\begin{array}{l}-10,634^{* * *} \\
(0,982)\end{array}$ & $\begin{array}{l}1,133^{* *} \\
(0,546)\end{array}$ \\
\hline \multirow{2}{*}{$t=2010$} & \multirow{2}{*}{$\begin{array}{l}-1,327^{* * *} \\
(0,356)\end{array}$} & \multirow{2}{*}{$\begin{array}{l}-4,865^{* * *} \\
(0,622)\end{array}$} & 0,229 & $5,989 * * *$ & $1,414 * * *$ \\
\hline & & & $(1,768)$ & $(1,319)$ & $(0,438)$ \\
\hline$t=2011$ & $\begin{array}{l}-2,062 * * * \\
(0,279)\end{array}$ & $\begin{array}{l}0,839 \\
(0,669)\end{array}$ & $\begin{array}{l}-0,594 \\
(1,669)\end{array}$ & $\begin{array}{l}2,446 * * \\
(1,169)\end{array}$ & $\begin{array}{l}-1,933 * * * \\
(0,412)\end{array}$ \\
\hline$t=2012$ & $\begin{array}{l}-2,725^{* * *} \\
(0,308)\end{array}$ & $\begin{array}{l}-9,447^{* * *} \\
(0,691)\end{array}$ & $\begin{array}{l}-10,966 * * * \\
(1,775)\end{array}$ & $\begin{array}{l}0,638 \\
(1,129)\end{array}$ & $\begin{array}{l}-1,284 * * * \\
(0,428)\end{array}$ \\
\hline$t=2013$ & $\begin{array}{l}-3,034^{* * *} \\
(0,368)\end{array}$ & $\begin{array}{l}-9,079 * * * \\
(0,646)\end{array}$ & $\begin{array}{l}-2,887 \\
(1,914)\end{array}$ & $\begin{array}{l}-15,531 * * * \\
(1,239)\end{array}$ & $\begin{array}{l}2,306 * * * \\
(0,602)\end{array}$ \\
\hline$t=2014$ & $\begin{array}{l}-3,489 * * * \\
(0,432)\end{array}$ & $\begin{array}{l}-7,310^{* * *} \\
(0,728)\end{array}$ & $\begin{array}{l}-13,209 * * * \\
(1,968)\end{array}$ & $\begin{array}{l}2,104^{*} \\
(1,260)\end{array}$ & $\begin{array}{l}2,367 * * * \\
(0,467)\end{array}$ \\
\hline$t=2015$ & $\begin{array}{l}-1,404^{* * *} \\
(0,398)\end{array}$ & $\begin{array}{l}-12,322 * * * \\
(0,781)\end{array}$ & $\begin{array}{l}-14,686^{* * *} \\
(1,950)\end{array}$ & $\begin{array}{l}-12,234^{* * *} \\
(1,302)\end{array}$ & $\begin{array}{l}-1,355^{* *} \\
(0,528)\end{array}$ \\
\hline$t=2016$ & $\begin{array}{l}-2,642 * * * \\
(0,415)\end{array}$ & $\begin{array}{l}-0,708 \\
(0,748)\end{array}$ & $\begin{array}{l}14,410^{* * *} \\
(2,002)\end{array}$ & $\begin{array}{l}-12,647 * * * \\
(1,185)\end{array}$ & $\begin{array}{l}0,365 \\
(0,484)\end{array}$ \\
\hline
\end{tabular}




\begin{tabular}{|c|c|c|c|c|c|}
\hline \multirow[b]{2}{*}{$\begin{array}{l}\text { Variável } \\
\text { independente }\end{array}$} & \multicolumn{5}{|c|}{ Variável dependente } \\
\hline & $\begin{array}{l}\text { IFGF Receita } \\
\text { própria }_{t}\end{array}$ & $\begin{array}{l}\text { IFGF Rigidez } \\
\text { orçamentária }_{\mathrm{t}}\end{array}$ & $\begin{array}{l}\text { IFGF } \\
\text { Liquidez }\end{array}$ & $\begin{array}{l}\text { IFGF } \\
\text { Investimentos }\end{array}$ & $\begin{array}{l}\text { IFGF Custo } \\
\text { da dívida }{ }_{t}\end{array}$ \\
\hline Constante & $\begin{array}{l}19,667 * * * \\
(3,267)\end{array}$ & $\begin{array}{l}50,272 * * * \\
(3,552)\end{array}$ & $\begin{array}{l}-10,988 \\
(8,831)\end{array}$ & $\begin{array}{l}9,495 * * \\
(4,723)\end{array}$ & $\begin{array}{l}16,247^{* * *} \\
(1,702)\end{array}$ \\
\hline Observações & 7.633 & 7.633 & 7.633 & 7.633 & 7.633 \\
\hline \multicolumn{6}{|l|}{$\begin{array}{l}\text { Efeitos fixos de } \\
\text { município }\end{array}$} \\
\hline Efeitos fixos de ano & Sim & Sim & Sim & Sim & Sim \\
\hline $\begin{array}{l}\text { Interceptos } \\
\text { aleatórios por } \\
\text { município }\end{array}$ & Sim & Sim & Sim & Sim & Sim \\
\hline
\end{tabular}

Notas: valores de IFGF e IFDM apresentam-se na escala 0-100. Todas as estimações utilizam o método de integração GaussHermite adaptativo, com 12 pontos de integração. Erros padrão do tipo bootstrap são apresentados entre parênteses. $* * *$ $p<0,01, * * p<0,05, * p<0,10$.

Fonte: elaboração própria.

Tabela A2 | Municípios com cinco ou mais observações de LISA (alto-alto ou baixo-baixo) estatisticamente significantes

\begin{tabular}{|cccccc|}
$\begin{array}{c}\text { Observações } \\
\text { Alto-Alto }\end{array}$ & Município & $\begin{array}{c}\text { Região } \\
\text { intermediária }\end{array}$ & $\begin{array}{c}\text { Observações } \\
\text { Baixo-Baixo }\end{array}$ & Município & $\begin{array}{c}\text { Região } \\
\text { intermediária }\end{array}$ \\
\hline 10 & Contagem & Belo Horizonte & 8 & Iturama & Uberaba \\
\hline 10 & Ibirité & Belo Horizonte & 7 & Carneirinho & Uberaba \\
\hline 9 & $\begin{array}{c}\text { Belo } \\
\text { Horizonte }\end{array}$ & Belo Horizonte & 6 & $\begin{array}{c}\text { Morada Nova } \\
\text { de Minas }\end{array}$ & Divinópolis \\
\hline 8 & Santa Luzia & Belo Horizonte & 6 & Três Marias & Belo Horizonte \\
\hline 6 & Consolação & Pouso Alegre & - & - & - \\
\hline 5 & Munhoz & Pouso Alegre & - & - & - \\
\hline
\end{tabular}

Fonte: elaboração própria. 
Figura A1 | Mapa de autocorrelação espacial local (LISA) do resíduo (diversos anos)

a) Regiōes intermediárias

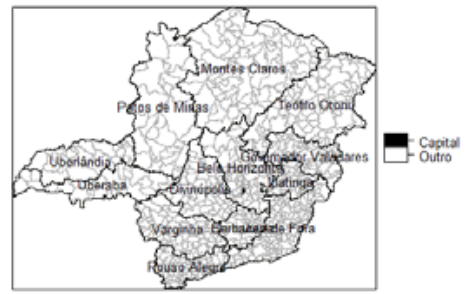

c) 2007

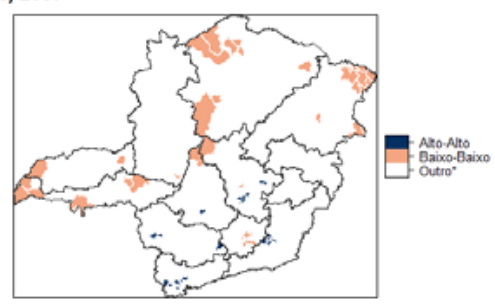

e) 2009

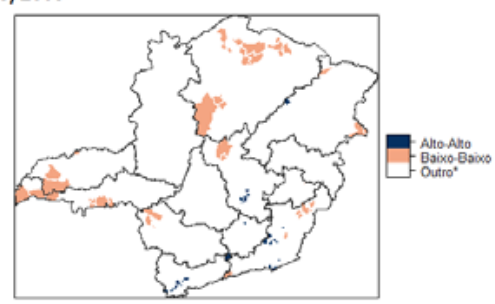

g) 2011

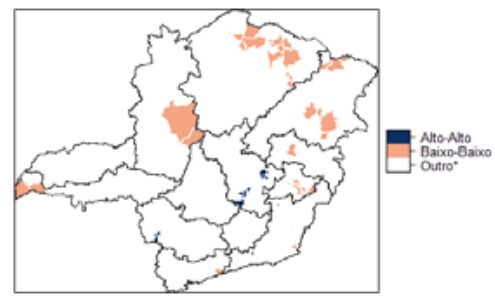

b) Média 2007-2016
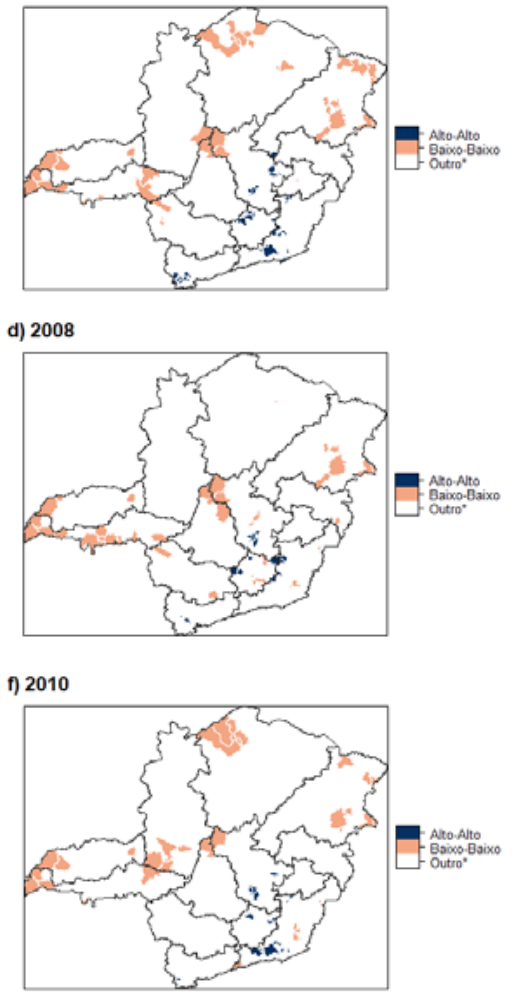

h) 2012

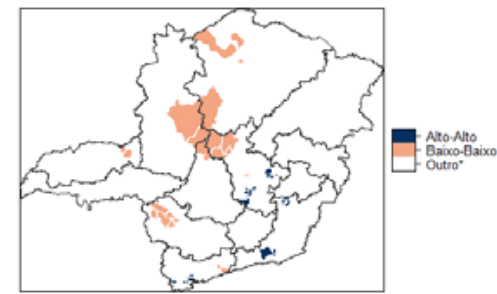


i) 2013

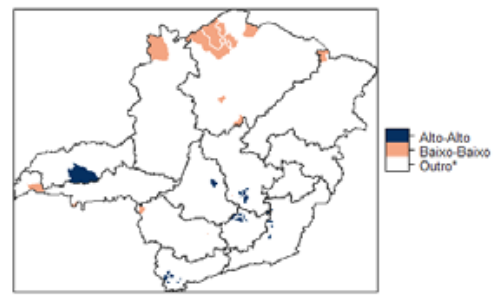

k) 2015

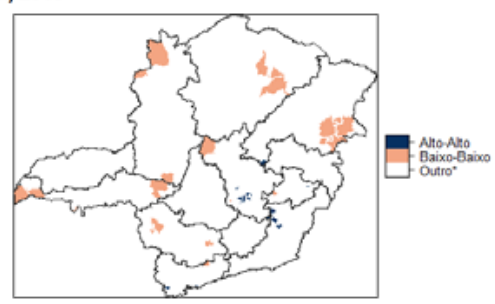

j) 2014

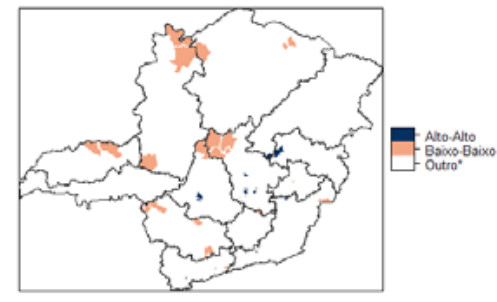

I) 2016

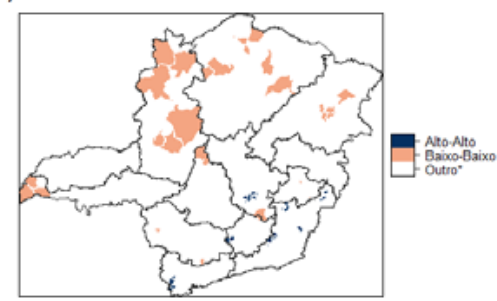

Nota: * LISA misto (alto-baixo, baixo-alto) ou não estatisticamente significante a 5\%.

Fonte: elaboração própria. 